\title{
Why are older investors less willing to take financial risks?
}

Article

Accepted Version

Creative Commons: Attribution-Noncommercial-No Derivative Works 4.0

Brooks, C., Sangiorgi, I., Hillenbrand, C. and Money, K. (2018) Why are older investors less willing to take financial risks? International Review of Financial Analysis, 56. pp. 52-72. ISSN 1057-5219 doi: https://doi.org/10.1016/j.irfa.2017.12.008 Available at https://centaur.reading.ac.uk/74683/

It is advisable to refer to the publisher's version if you intend to cite from the work. See Guidance on citing.

To link to this article DOI: http://dx.doi.org/10.1016/j.irfa.2017.12.008

Publisher: Elsevier

All outputs in CentAUR are protected by Intellectual Property Rights law, including copyright law. Copyright and IPR is retained by the creators or other copyright holders. Terms and conditions for use of this material are defined in the End User Agreement.

\section{www.reading.ac.uk/centaur}

\section{CentAUR}

Central Archive at the University of Reading

Reading's research outputs online 


\title{
Why are older investors less willing to take financial risks?
}

\author{
Chris Brooks* \\ ICMA Centre, Henley Business School \\ Ivan Sangiorgi \\ ICMA Centre, Henley Business School \\ Carola Hillenbrand \\ John Madejski Centre for Reputation, Henley Business School \\ Kevin Money \\ John Madejski Centre for Reputation, Henley Business School
}

October 2017

\begin{abstract}
We investigate the link between age and tolerance of financial risks in the context of attitude to risk questionnaires completed by clients when meeting their financial advisors. Using a unique database comprising the responses to over half a million such questionnaires, we show that risk tolerance declines at an increasing, albeit slow, rate with age. We investigate the explanatory power of the ability to bear losses, declining investment horizon and retirement effects, finding that these variables have considerably greater explanatory power for the cross-section of risk aversion than age, and that they are only able to partially mediate the link between age and risk tolerance. We are unable to uncover any evidence that declining cognitive abilities among older investors are able to explain their lower willingness to take financial risks. Overall, our results are indicative of a modest age effect in risk tolerance that cannot be attributed to changes in other observable characteristics that differ between younger and older investors.
\end{abstract}

Keywords: retail investors, risk tolerance, attitude to risk, effect of ageing, cognitive decline

J.E.L. Classifications: G11, G20, J14, C25

Corresponding author: Chris Brooks, ICMA Centre, Henley Business School, University of Reading, Whiteknights, Reading RG6 6BA, UK; tel: (+44) 118378 7809; e-mail: C.Brooks@reading.ac.uk

Acknowledgements: We are grateful to the ESRC for funding this research under grant number ES/P000657/1. We would like to thank Distribution Technology for supplying the data used in this paper. We are also grateful to seminar participants at the Behavioural finance Working Group and to Arthur Money and Heather Richards for their constructive comments. 


\section{Introduction}

Making appropriate financial decisions is one of the most important choices an individual may face during their lifetime. Pension saving in particular has become increasingly important with ever-growing longevity implying a need to ensure that savings and investments are adequate (Antolin, 2010). Following changes announced in the UK budget in 2014, pension investors have been given new powers to withdraw their defined contribution pension savings from age 55 which can then be spent or self-invested as they choose. ${ }^{1}$

Yet making optimal financial decisions is apparently becoming harder. It is widely believed that the financial markets are growing ever-more complex with an increasing array of potential investments to choose from. For example, structured products are commonly available but are often hard for retail investors to understand since they represent sophisticated hybrids of traditional assets with complex payoff structures (Bluethgen et al., 2008; Hunt et al., 2015).

The information processing demands placed on investors when making choices are phenomenal as finance has a unique language which is itself evolving; the investment and tax frameworks also seem to be in a constant state of flux so that what is an optimal approach in a given tax year may not be so in the next. There is evidence that retail investors face substantial costs to acquire information and suffer from numerous cognitive deficiencies and biases that get in the way of making rational strategic choices to a greater extent than professionals (Shapira and Venezia, 2001).

Numerous studies have observed that risk aversion increases with age (including Boyle et al., 2011; Bucciol and Miniaci, 2011; Jianakoplos and Bernasek, 2006; McInish, 1982; Morin and Suarez, 1983), most sharply for those in the lowest socio-economic groups (Schurer, 2015), and it has been suggested that this factor stands out above all others affecting risk tolerance (Clark and Strauss, 2008). As well as the evidence on the effects of age on risk tolerance from questionnaires and experiments, an examination of investors' actual portfolios (from the very limited number of studies that investigate this) corroborates the view that older investors take less risk since their holdings in equities and other higher-risk investments are both lower (Bellante and Green, 2004; Kumar, 2009; see also Bailey et al., 2003). Older investors also demonstrate a much-reduced willingness to take risks with profits already achieved (Henninger et al., 2010) and have higher discount rates (Albert and Duffy, 2012; James et al., 2015), although they are no less likely to take risks within a gain frame (Kurnianingsih et al., 2015; Samanez-Larkin et al., 2007).

Furthermore, there is some suggestion that the relationship between risk aversion and age is non-linear - for example, Riley and Chow (1992) and Faff et al. (2008) suggest that it declines until age 65 but then rises

\footnotetext{
${ }^{1}$ This is set to rise to 57 years of age from 2018. For details, see 'Freedom and Choice in Pensions', HM Treasury, March 2014.
} 
thereafter, while Faff et al. (2011) find that it increases continuously with age but at an increasing rate. Yet there also exist other studies suggesting that risk aversion actually declines with age (e.g., Bommier and Rochet, 2006; Grable, 2000; Wang and Hanna, 1997). Differences in findings across studies concerning the link between age and risk tolerance may be partly reconciled by observing the inconsistent definitions of elderly investors employed across studies, which may vary from mid-50s to over 70s (Henninger et al., 2010, p.268), and differences in the methodologies used (with some studies using lab-based experiments, others surveys, and others still examining actual portfolio holdings).

While much of the existing evidence on the link between age and risk tolerance is drawn from US experiments, experiences or portfolios (e.g., Albert and Duffy, 2012; Boyle et al., 2012; Bucciol and Miniaci, 2011; James et al, 2015; Henninger et al., 2010; Yao et al., 2011), some research has also been conducted in the context of Germany (Dohmen et al., 2011), Australia (Bateman et al., 2011), Norway (Fagerang et al., 2016), Singapore (Kurnainingsih et al., 2015), and Ireland (Larkin et al., 2013). Despite the possibility for important cultural variation, differences in default retirement ages and the relative importance of state versus private pension provision, no obvious systematic differences in the patterns across countries emerge. We have been unable to uncover any comparable evidence for the UK.

In summary, while there is not universal agreement among researchers, the general consensus is very strongly that older investors are less risk tolerant. A possible explanation of this phenomenon that has garnered widespread support is that it results from cognitive decline with age so that such investors have more limited memory, and they process data more slowly and less accurately. For example, young people are more likely than the old to be able to get to grips with detailed information, while the elderly can only grasp the essence of ideas (Tun et al., 1998) due to changes in the frontal lobe (Rajah et al., 2010). ${ }^{2}$ The elderly often have greater difficulties multi-tasking than the young, and it may be that their cognitive resources are already exhausted in functioning effectively during their employment or performing day-to-day tasks (Verhaeghen and Cerella, 2002), so that there is little left for the effective assessment of financial risks, which are then avoided entirely.

From a neurological perspective, this weakened performance is associated with both a reduction in the dopaminergic reward function and more temporal variability in the nucleus accumbens (Weierich et al., 2011). Only modest changes in cognitive function may be required to precipitate large changes in behaviour (Salthouse, 2001). Ageing typically results in reductions in both working memory and information processing speed (Park and Reuter-Lorenz, 2009; Salthouse, 1990). Rypma et al. (2001) show that the information processing power of the prefrontal cortex declines as individuals age, leading experiences and emotions to have an increased role in decision-making. This possibly reduces psychological resilience to investment losses and leads to a heightened tendency to sell risky assets at their lowest points following heavy losses (Browning

\footnotetext{
${ }^{2}$ This finding is contested, however, with Kovalchik et al. (2005) arguing that decision-making among healthy older adults is similar to that of 20 -year olds.
} 
and Finke, 2015), which causes an average potential return loss of 1.6\% per year (Friesen and Sapp, 2007). A reduced capacity to determine and limit risks may encourage older investors to avoid taking such risks in the first place (Yao et al., 2011).

Older investors are likely to have longer investment histories to draw upon when setting current financial environments into context, probably having witnessed several previous periods of market booms and busts (Yao et al., 2011). However, changes in affective processing of information may more than offset this, leading them to focus even more than youngsters on recent experiences (Weierich et al., 2011). Older investors are more likely to project their current feelings into the future (Gilbert and Wilson, 2009). It appears to be the slower, more deliberative decision-making tools required for effective financial selection that are weakened with age, whereas the fast, automatic, reactionary processes remain relatively intact (Hess, 2015), linking with a tendency among the elderly to excessively focus on recent information and performance. Older investors also exhibit a greater need for 'cognitive closure', being intolerant of ambiguity and uncertainty, which makes them more inclined to make rapid decisions (Koscienlniak et al., 2016; Kruglanski and Webster, 1996).

It is not clear, though, whether the process of ageing on average causes simultaneous but independent declines in cognitive ability and risk tolerance, or whether it is the decline in cognitive ability as an investor ages that causes the reduction in risk tolerance as suggested, for example, by the results of James et al. (2015). Browning and Finke (2015) find support for the latter in that once they control for cognitive power, the relationship between age and flights from stocks after the financial crisis disappears. Henninger et al. (2010) suggest that information processing rapidity and strength of memory act as mediators to age-related effects on risk aversion, so that when the former variables are incorporated into models to explain risk aversion, the impact of the latter is no longer significant. Boyle et al. (2012) also confirm this mediating effect, but to a lesser extent. Hence these studies argue that it is not getting older per se that causes changes in appetite for risk, but rather the neurological declines that typically accompany it. Thus, a decline in risk tolerance is not inevitable for those among the elderly who are able to maintain their powers of information processing and recall. Boyle et al. conclude by proposing non-cognitive explanations for changes in risk-taking behaviour later in life, such as gradual changes in personality traits including neuroticism or a declining willingness to try new things.

The existing literature has a tendency to consider the elderly as a homogeneous group with a fixed set of characteristics; however, while this was probably never an entirely accurate assessment, it is now even less appropriate than before for several reasons. First, longevity has been increasing rapidly, so that now a healthy 60 -year old in the UK can expect to live for a further 24 years (albeit with a large standard deviation), ${ }^{3}$ making it ever more important that retirement savings are not expended too quickly. Second, following the abolition of mandatory retirement ages in the US through an Amendment to the Age Discrimination in Employment Act

\footnotetext{
${ }^{3}$ Source: Global Age Watch Index, 2015: http://www.helpage.org/global-agewatch/population-ageing-data/life-expectancy-at-60/
} 
in 1986 and in UK through the Employment Equality (Age) Regulations Act of 2006, the transition between employment and retirement is no longer an abrupt event taking place at age 60 or 65 . Rather, it is a much more fluid concept, with some who can afford it choosing to stop work in their 50s (e.g., those in certain public sector roles with defined benefit schemes - see Mein et al., 2000), while others may phase their retirement, working part-time for some years before leaving the workforce altogether. Finally, others still may continue to work full-time for as long as they are physically able - into their 70s and possibly beyond (Walker, 2002).

Given the heterogeneity of the elderly as a group, the changing nature of old age, and the lack of agreement in the existing literature regarding its effects on attitude to risk, it is prescient that the link between age and risk tolerance is revisited within a multi-causal framework that allows for a range of other relevant factors so that the impact of age per se can be isolated. Employing a new database of the responses more than half a million adults making financial decisions using a psychometric risk profiling questionnaire, we examine how financial risk tolerance varies with age, allowing for a range of other demographic factors. Using a set of unique features of our data, we are also able to separate the impact of the client's capacity to bear losses and their investment horizon from their pure risk tolerance. We are able to control for gender effects, retirement effects, wealth effects, investment experience effects, and the impact of marital status. We evaluate the mediating impact that these variables may have on the link between attitude to risk and age. In addition, by exploiting additional detailed information from the manner in which clients complete the questionnaire and the consistency between their answers, uniquely we are also able to examine whether there are any differences between clients of differing ages that may relate to variations in their cognitive abilities rather than age per se. We show that while the explanatory power of the control variables for the cross-section of attitude to risk scores dwarfs that of age, there still remains a statistically significant pattern of older investors preferring to take less risk.

The remainder of this paper develops as follows. We first discuss the context in which our data are captured and describe its features in Section 2. Here we also present the methodology that is employed to conduct the main analysis. The results and findings are then presented and discussed in Section 3 with conclusions drawn in Section 4.

\section{Data and Methodology}

\subsection{The Advisory Setting}

Our study exploits a unique dataset that is, to the best of our knowledge, many times larger than anything available in the existing literature at over half a million observations. The data are obtained from Distribution 
Technology (DT), a UK-based provider of financial planning and front office wealth management systems. ${ }^{4}$ Many existing studies employ data over a fairly narrow age range, whereas ours covers people at every stage of their adult life, which we truncate at ages from 18 to $100 .{ }^{5}$ Thus, a further benefit of our dataset and approach is that we make no a priori judgement as to what constitutes old age, since the sample includes large numbers of respondents from high-school leaving age up to those well into their $90 \mathrm{~s}$. This is important since the evidence on when cognitive changes begin to have a significant impact upon risk-taking behaviour is mixed and might have been anticipated to have increased over time along with retirement ages and health life expectancy. Fein et al. (2007) observe that the dip in performance on the Iowa Gambling Task takes place around age 55, while Korniotis and Kumar (2011) do not observe a decline in decision-making skill until 70. In addition, it has been suggested in the literature that middle-aged adults might make the best financial decisions - having the benefit of both experience and retained cognitive abilities (Agarwal et al., 2009; Kurnianungsih et al., 2015) and yet almost all existing studies compare only the young and old while omitting the middle aged entirely from the analysis.

We now describe the context in which the financial risk tolerance assessments captured in our database are made. DT's core product, 'Dynamic Planner' is used by large numbers of independent financial advisors (IFAs) and wealth managers. Many retail investors make financial decisions following advice from an intermediary such as an IFA, with the advisory process typically involving several steps. The first stage is usually that the advisor asks the client to complete a risk profiling (also known as an attitude to risk or ATR) questionnaire as part of a wider discussion between them to ascertain the client's characteristics, lifestyle, level of wealth and salary, life expectancy and future investment goals.

DT provides two versions of the ATR questionnaire, including 10 and 20 questions (with the former being a subset of the latter); it is at the advisor's discretion which of the two is employed, and they are chosen in roughly equal proportions. ${ }^{6}$ Each of the 10 or 20 questions is scored on a five-point Likert scale from 'Strongly Disagree' through 'Neither Agree nor Disagree' to 'Strongly Agree'. An aggregate integer result from 1 (lowest level of risk tolerance) to 10 (highest possible risk tolerance), which we term the 'calculated ATR score', is then formed by summing the scores from the individual questions. The process of risk profiling involves sensitising the client to the concept of a risk premium - in other words, the trade-off that is believed to exist between higher risk investments with potentially higher returns on the one hand and lower risk products

\footnotetext{
${ }^{4}$ DT serves over 500 advisory firms and works with more than 100 asset management firms to risk profile their funds and portfolios, representing more than $£ 150$ bn in invested assets. 200,000 clients complete DT’s risk profiling questionnaire per year with $£ 2$ billion of client recommendations made in 2016 using Distribution Technology's Dynamic Planner interface.

${ }^{5}$ A small number (only $0.875 \%$ of the initial dataset) of clients are recorded in the database as having ages outside this range; however, we attribute these to either data entry errors, or to advisors testing the system with dummy clients and we therefore truncate the sample in this way.

${ }^{6}$ There is no a priori reason for which advisors would prefer to use the 10 or 20 questions. However, investors who answer the 20 question version are slightly more risk tolerant (see for instance Table 1), and wealthier (unreported statistics). The latter result is intuitive if advisors use the longer questionnaire with clients whom they consider to be of higher value.
} 
but with less potential for large profits on the other. The advisor employs the ATR questionnaire to establish where the client most comfortably sits on this spectrum of risk tolerance.

The meeting between advisor and client usually has several objectives - as well as assessing the latter's appetite for risk through the completion of an ATR questionnaire, they provide broad evaluations of financial literacy or experience and an evaluation of the client's capacity to bear losses, their investment horizon, and whether the client may need access to the money to cover unforeseen circumstances. The financial advisor will blend information from these additional questions on capacity to bear losses and the more general discussion with the client to arrive at a final integer number on the 1-10 scale, which we term the 'selected ATR score'. This selected ATR score may be lower, higher, or the same as the corresponding calculated ATR. ${ }^{7}$

Once the risk tolerance and risk capacity of the client has been established, the next stage is usually for the IFA to propose suitable investment products based on the selected ATR. The presumption is that customers willing to take considerable risks (highly risk tolerant) will be offered appropriate risky investment opportunities (for example, involving overseas shares, corporate bonds, and commodities) while those who are uncomfortable with financial risks will be offered lower risk products (e.g., involving government bonds or cash-like investments). It is a requirement of DT's system that clients' completed ATRs, capacity responses, age and gender are recorded on-line. Other information, such as the client's investable wealth, employment status, health status, etc. may also optionally be recorded onto Dynamic Planner, or maybe captured off-line by the advisor and so our observation of these additional demographics is less complete, albeit the numbers of data points available (tens of thousands) are nonetheless still very large.

Much of the existing evidence base arises from gambling tasks completed in an artificial setting, such as the Iowa Gambling Task, the Cambridge Gambling Task or the Balloon Analogue Risk Task. Additionally, most such studies involve fairly small samples of around 50-100 of two groups of participants: undergraduate students representing the young, and older adults drawn from the more general population. Since our data arise as part of a real financial decision-making process, they have the significant advantage that participants are making real choices and thus our sample does not suffer from the 'hypothetical bias' that would beset any study where the questions were asked as part of a purely academic experiment or as part of a more general survey as is common in the literature (see, e.g., Holt and Laury, 2005). Camerer and Hogarth (1999) and Smith and Walker (1993) suggest that sufficient financial incentives are required to make participants behave

\footnotetext{
${ }^{7}$ It would be interesting for future research to examine whether clients who have greater trust in their advisor are more willing to entertain portfolios with risks that differ more significantly compared with their revealed preferences than clients who do not, as Patacchini and Rainone (2017) suggest; similarly, it would be of interest to examine whether the difference between the calculated and selected ATR is greater for older than younger clients resulting from an assumption on the part of advisors about what such investors are likely to require. Indeed, Kara and Molyneux (2017) go further and suggest that outright discrimination may be taking place in the context of the UK mortgage market.
} 
rationally. The size of our sample also ensures that it captures a rich diversity of decision-makers in terms of age, wealth, employment type etc.

\subsection{Data Summary}

Panel A of Table 1 presents summary statistics for the dataset we employ, focusing specifically on age, which we split into 5-year buckets in each row, with the averages for all ages being presented in the final row. A total of $579,382^{8}$ completed questionnaires provides a good spread of ages at the time of completion, although this peaks for the 50-69 intervals. More men than women complete the questionnaire (overall, men make up roughly $60 \%$ of the sample) at all ages up to 75 , by which time the lower longevity of the former has taken its toll. The mean ATR score (1-10 scale) is reported in the fifth column for all respondents, which is then separated into men and women in the following two columns. Several interesting patterns are evident. First, at this stage incorporating no controls, the mean risk tolerance increases slightly from 5.7 at age $<30$ to 5.9 at 35 45 , before declining monotonically thereafter to reach 4.7 at age $80+$. Men are statistically significantly more risk tolerant than women within all age buckets, although the difference declines with age from around 0.6 at ages below 50 to 0.3 at $80+$. The median ATR, in the penultimate column of Table 1, is 6 at all ages to 54 when it falls slightly to $5 .{ }^{9}$

\section{[Insert Table 1 about here]}

The standard deviations in the final column fall monotonically from 1.5 at $<30$ to 1.27 at $80+$, although this magnitude indicates that while risk tolerance declines with age, there is very considerable heterogeneity within each group. During old age, and in particular in its later stages, leaving a bequest may be the primary motivator for continuing to save, and in such circumstances clients may be less risk averse than if their funds are required to meet more pressing living expenses (Feinstein and Lin, 2006), and it might be that clients with such a motive may be more risk tolerant.

Panel B of Table 1 presents summary statistics for age, which is the explanatory variable of most interest in our analysis. The median age of respondents is 58, with a standard deviation of 13 and a range from 18 to 100. ${ }^{10}$ Panel C presents Spearman's correlations between the five most important variables of interest: age, the calculated ATR score, and the responses to the three 'capacity questions': capacity for loss; timeframe;

\footnotetext{
${ }^{8}$ We discard around $4.7 \%$ of the original observations to account for those clients who answer more than six (12) questions in the 10(20)-question version as middle answers ('Neither Agree nor Disagree'), which are taken to indicate a sufficient lack of engagement with or misunderstanding of the process that their responses may not be useful in measuring their risk tolerance. This $60 \%$ threshold is also consistent with market practice adopted by DT and such cases would trigger a warning for advisors on the system.

${ }^{9}$ We are aware that strictly it is not valid to conduct tests of significance in the classical framework when the data can only take a narrow range (1-10) of integer values; however, we nonetheless follow much of the literature in doing this when discussing the summary statics.

${ }^{10}$ As discussed above, we truncate the sample at both ends by dropping all data where age is $<18$ or $>100$, since we believe that there is a high chance that such entries would be either erroneous or represent cases where advisors are testing the system with 'dummy clients'.
} 
liquidity. ${ }^{11}$ As one would expect given the vast sample size, all correlations are significant at the $1 \%$ level except for that between age and capacity, which is significant at $5 \%$. Intuitively, the calculated ATR score is negatively correlated with age (-0.23), but positively correlated with capacity for loss $(0.40)$, timeframe $(0.19)$ and liquidity (0.09). Again, as expected, the three capacity questions themselves are negatively correlated with age, so that older investors have lower capacity for losses, shorter time horizons and are more likely to need to cash in the investment at short notice, than younger investors.

It has been suggested in some studies that risk tolerance is time-varying, and declines following periods of economic turbulence or very poor investment returns (e.g., Grable et al., 2006; Tausch and Zumbuehl, 2016; Yao et al., 2004). Bateman et al. (2011) observe a very modest moderation in risk tolerance immediately following the financial crisis period of 2008, although it did not affect the relative risk tolerance of young versus old or wealthy versus less affluent, a finding echoed in Gerrans et al. (2015). However, it is also widely believed that risk tolerance is a deep-seated and stable characteristic relating to an individual's personality type, social and economic position, and psychosocial factors (Filbeck et al., 2005) that will vary very little, even over long periods (see, for example, Roszkowski and Davey, 2010). McCrae and Costa (1994) suggest that personality traits are crystallised by age 30 and only vary very slowly thereafter, while Alan et al. (2017) identify a link between the risk preferences of mothers and of their daughters from as early as seven years old. It is therefore not clear whether periodically observed switches away from risky assets ('flights to quality') and eventually back again reflect changing risk tolerance or merely the result of investors updating their expectations of future risk and returns as more information becomes available so that risky assets no longer provide the required premium and are sold. Hence apparent changes in risk preferences may merely reflect modifications in risk perception (Dohmen et al., 2011). Survey evidence in Weber et al. (2013) supports this explanation that changes in portfolio composition following the financial crisis in 2008 can be explained by updates in subjective risk and return predictions.

We are able to shed light on this issue by considering the extent to which the calculated attitude to risk varies over our sample period and whether any notable peaks or troughs correspond with significant events in the financial markets or wider economy. In Figure 1, Panel A we plot the (monthly) variation over time of the average Calculated ATR versus the (monthly) variation over the sample period of the number of clients from 1 January 2011 to 31 August 2016. The average Calculated ATR is remarkably stable over time and aligned to its sample mean value of 5.35, indeed suggesting that risk tolerance does not vary noticeably with changes in the underlying economic or financial environments. This result contrasts with some of the literature using surveys of undergraduates in a lab setting, such as Guiso et al. (2017), who find that a financial crisis leads to

\footnotetext{
${ }^{11}$ Capacity, time and liquidity are more fully defined in Section 2.3 .
} 
an emotional affect similar to watching a horror film combined with a decline in risk tolerance even among those who have not themselves suffered losses.

[Insert Figure 1 about here]

Figure 1, Panel B plots the calculated ATR score by age bucket for all clients and also separated out by gender; the feint dashed lines represent \pm 2 standard error bands. ${ }^{12}$ It is apparent that, before controlling for any other variables, risk tolerance rises very slightly from age $<30$ to $35: 39$ before falling continually thereafter. Figure 1, Panel B also shows that men are more risk tolerant for all age groups, although the gap between genders declines by about one third with increasing age.

Figure 2 plots the surface of estimated absolute probabilities ${ }^{13}$ for each age bucket and for each calculated ATR, based on the specification presented in Table 2. The surface describes the probability of an investor being allocated to a certain Calculated ATR score if his/her age is in a given bucket. The probability distribution is more skewed to the left as age increases. In other words, the older is the investor, the more probable he/she is to be allocated to lower attitude to risk levels. In general, investors aged less than 55 years are more likely to be allocated to a Calculated ATR score equal to 6, with probabilities ranging from $26.27 \%$ for the age bucket 50-54 to $27.35 \%$ for the age bucket 35-39, followed by a score of 5 and 7 . Investors aged more than 55 years old are more likely to be allocated to a Calculated ATR score equal to 5, with probabilities ranging from $27.54 \%$ for the $55-59$ age bucket to a maximum of $28.26 \%$ for the $70-74$ age bucket, followed by a score of 4 and 6 .

[Insert Figure 2 and Table 2 about here]

The difference between 30-year old (or younger) and an 80-year-old (or older) shows more clearly the impact of age on the probability distribution of the ATR. On the one hand, the probability of being assigned to an ATR score of 6 and 7 is $8.16 \%$ and $11.27 \%$ respectively higher for clients aged less than 30 years with respect to an 80 -year-old (or older). On the other hand, the probability of being assigned to an ATR of 3 or 4 is $8.57 \%$ and $11.36 \%$ lower for 30-year-old (or younger) clients than for 80 -year-old (or older) clients. In total 18.97\% of 30 -year-old clients and $42.71 \%$ of 80 -year-olds are likely to be allocated to a risk tolerance lower than or equal to 4 .

\subsection{Methodology}

\footnotetext{
${ }^{12}$ An ordered probit regression with time-fixed effects is employed in order to produce this summary plot - this is explained in the following sub-section.

${ }^{13}$ We have also computed marginal probabilities instead of absolute probabilities since it is common practice when estimating ordered probit regressions. Results are quantitatively and qualitatively in line with the reported probability surface.
} 
The key question we seek to address is whether attitude to risk varies systematically with age and if so, whether we can explain this variation using a pre-specified set of variables that capture the changing nature of the sample of respondents with age. In other words, is it age per se that affects ATR or does it act as a proxy for some other factors that also vary systematically with age? Thus the dependent variable ${ }^{14}$ in the following regressions will be the calculated ATR score of investor $i$. Since this is limited to take one of a narrow range of integer values (1-10) only, OLS would be an inappropriate estimation technique and we therefore employ ordered probit ${ }^{15}$ in all of the subsequent analysis. We begin with a simple model incorporating a limited number of control variables which we then gradually extend. The model is of the form:

Prob. Calculated ATR $R_{i}=\alpha^{\prime}+\beta_{1}$ Age $_{i}+\beta_{2}$ Age $_{i}{ }^{2}+\beta_{3} 10$ QuestionVersion $_{i}+\beta_{4}$ Male $_{i}+\gamma_{i}{ }^{\prime} X_{i}+\epsilon_{i}$

where $\alpha^{\prime}$ is a vector of cut-off points which are usually estimated in ordered probit models ${ }^{16}$ (constant terms); $\epsilon_{i}$ stands for the i.i.d. standard normal error term; $A g e_{i}$ is the investor's age and is measured in years (and fractions thereof), and the parameter estimate on $\mathrm{Age}_{i}{ }^{2}$ is multiplied by 1,000 for ease of presentation. We add a dummy 10 QuestionVersion ${ }_{i}$ which takes value of one when the investor completes the 10-question version of the questionnaire, and zero otherwise. A longer questionnaire could be perceived as being more accurate than a shorter questionnaire and thus the measured ATR score less susceptible to noise provided that boredom has not set in so that the client no longer takes care when completing the remaining questions. As a consequence of the latter, investors could answer less consistently and engage less the longer the questionnaire. As a result of the noise/boredom trade-off we do not have any a priori expectation of the sign on this variable. Male $_{i}$ is a dummy equal to one investor's gender is male, ${ }^{17}$ and zero otherwise. $X_{i}$ is a vector of additional explanatory variables which we summarise into four categories: risk capacity, demographic factors, health status and cognitive mediators in the relationship between age and ATR. $X_{i}$ consists of the following variables.

Proxies for financial ability to withstand risk:

Capacity: It is the investor's financial ability to bear losses (e.g. the extent to which their employment income exceeds their outgoings). It is measured as a score variable which takes the value of zero when the ability is none or limited $(\mathrm{N})$, of one when the ability is small or medium (M), and of two when the investor states that even large losses would have a low impact on their future lifestyle (i.e. large capacity to withstand losses), (L).

Time: It is the client's investment time horizon. It is measured as a score variable with values ranging from zero to two according to whether the time horizon is short $(\mathrm{S})$, medium $(\mathrm{M})$ or long $(\mathrm{L})$. The time horizon is

\footnotetext{
${ }^{14}$ The dependant variable estimated in ordered probit models is latent unobserved probability and it is usually computed as a z-score. The probability of an ATR score $j=1,2, \ldots, 10$ is calculated as the probability that the estimated regression model, plus an error term, is within a range of values (cut-off points) specific to the outcome $j$, which is the overall calculated risk tolerance score.

${ }^{15}$ Estimation of ordered probit models is based upon maximum likelihood.

${ }^{16}$ We do not report the estimated cut-off points for brevity.

${ }^{17}$ Gender is an important control variable given the overwhelming finding that men are more risk tolerant across a variety of domains (e.g., Borghans et al., 2009).
} 
less than five years for short term investments (S), between five and ten years for medium term investments (M), and more than ten years for long term investments $(\mathrm{L}){ }^{18}$

Liquidity: It is the investor's perception of how likely it is that they would need access to the investment under consideration if they hit unforeseen circumstances. It is a score variable (values in the range 0-2) which equals zero if the investor is likely to need access to his/her investments due to a lack of alternative resources (L), one if the investor might need access and his/her liquidity is medium (M), and two if the investor reports that they have other savings which they could use for most needs and thus their liquidity is high $(\mathrm{H}) .{ }^{19}$

We expect that the higher is the financial ability to bear risks (so the higher the capacity, the longer is the time horizon, and the higher is the liquidity need), the more likely it is that the investor to be more risk tolerant. ${ }^{20}$

Proxies for demographic and investment factors:

Employment Status: It is a set of dummy variables which reflect the investor's employment status. The possible statuses ${ }^{21}$ are Employed, Retired, Semi-Retired, Self-Employed, Director or Partner, Temporarily Employed or Contracted, and Non-Working. ${ }^{22}$

Marital Status: It is a set of binary variables which takes value of one according to the marital status of the investors. Dummy variables are Civil Partnership, Married, Divorced and Widowed. ${ }^{23}$

Investment Wealth: It is the investable wealth of the clients measured in thousands of pounds. We expect that the wealthier is the investor, the more likely is the calculated ATR to be higher.

Investment Experience: It captures both the investor's self-assessed level of experience in investing and his/her level of financial literacy. It takes integer values from zero to two according to whether the investor is not at all experienced and not very comfortable with investing (zero), whether he/she has medium level of experience and literacy, or whether the she is comfortable with investing and has some understand potential financial risks and rewards. We expect that the higher the investment experience, the more probable is the investor to be more risk tolerant.

\section{Proxies for health status:}

\footnotetext{
${ }^{18}$ Bommier and Rochet (2006) show that risk tolerance typically increases with planning horizon, which may diminish the usual impact of ageing (where investment horizons reduce) on risk tolerance.

${ }^{19}$ Note that 'liquidity' in this context refers to the other resources that the investor may have access to rather than the ease of sale of the investment under consideration.

${ }^{20}$ Note that, following guidance by the Financial Conduct Authority, risk tolerance and risk capacity are treated entirely separately within DT's process and the latter is not incorporated into the 10 or 20 questions that assess risk tolerance.

21 'Employed and Self Employed' is arbitrarily used as the base/reference category.

${ }^{22}$ Students, unemployed clients and house-persons are combined into the single category of 'Non-Working' investors.

${ }^{23}$ We select 'Single' as the base category of all marital statuses. In unreported univariate results, we find that single investors are statistically more risk tolerant than other investors.
} 
Good Health: It is the investor's self-assessment of his/her health condition. It is a binary variable which takes value of one if health is considered good by the investor, and zero otherwise. We expect that the better is the investor's health, the more risk tolerant he/she is likely to be.

Smoker: It is the investor's smoking behaviour. It equals one if the investor regularly smokes, and zero otherwise. We expect that investors with smoking habits are more likely to be more risk tolerant as smoking is usually considered a risky activity in the health context.

\section{Proxies for cognitive mediators between age and ATR:}

Standard deviation of responses: This variable captures both the extent to which the investor is engaging with the questions when completing the questionnaire and the level of consistency in his/her responses. In other words, a very low standard deviation would indicate that the client has ticked the middle response a very high proportion of times, suggesting that the process was not being taken sufficiently seriously or that the questions were not being understood. At the other extreme, a very high standard deviation would suggest an inconsistency in the assessment of risk across the questionnaire as a whole and a high degree of noise in the responses, which may relate to reduced cognitive ability (Andersson et al., 2016).

Absolute deviation of similar questions: It is the investor's ability to answer similar questions with similar responses, measured as the average across four pairs of questions of the absolute deviation between each of the two similar questions. We expect that a higher average absolute deviation would demonstrate a lack of focus or concentration on the task at hand, and in line with the literature discussed above, the more likely is the investor to be less risk tolerance.

In all specifications, we allow for time fixed effects via year dummy variables. We are most interested in the combined effects of the Age and $\mathrm{Age}^{2}$ variables. Therefore, for ease of interpretation, in the penultimate row of the results tables we also present an estimate of the model-fitted difference between the ATR score that would be expected for an 80-year-old compared with a 30-year-old, and these two extremes effectively demonstrate the effect that age can have on ATR. ${ }^{24}$ We additionally report the marginal probability of a Calculated ATR equal to $\operatorname{six}^{25}$ for all predictors in order to assess the marginal change in probability when the independent variables increase by one unit. ${ }^{26}$

\footnotetext{
${ }^{24}$ For both 30 -year-old and 80-year-old, we estimate the probabilities (margins) of a client being allocated to each of the 10 ATR scores based on the ordered probit estimation. We then compute for both ages the model fitted ATRs (expected value) by summing the products between each probability and the relative ATR score. Finally, the model fitted difference is the spread between the expected ATR score for 30-year-old and 80-year-old

${ }^{25}$ For brevity we report the marginal effects of only one possible ATR score. The choice is arbitrary and corresponds to the median calculated ATR for a young investor (see Table 1).

${ }^{26}$ It is common practice to assume that the remainder of the variables are at their mean values.
} 


\section{Results}

\subsection{Initial Results on the Link between Age and ATR}

Table 3 presents the core results ${ }^{27}$ on the link between age and the calculated ATR score. The column headed (1) includes only age and age-squared as explanatory variables, and the parameters on both are significant at less than the $0.1 \%$ level, suggesting that before we control for any other factors that might affect it, the ATR score declines at an increasing rate with age. Therefore, following Riley and Chow (1992) and Faff et al. (2008; 2011), we find that the relationship between risk tolerance and age is non-linear. The parameter estimates are highly plausible and have the expected signs, but are modest in magnitude, however, and suggest that ATR declines very slowly with age. The pseudo- $\mathrm{R}^{2}$ value for regression (1) is only around $1.5 \%$, suggesting that other factors may have considerably more explanatory power for variations in ATR across clients than age, and that there is substantial additional heterogeneity. If age increases by one year, the marginal probability ${ }^{28}$ of an ATR equal to six decreases by $0.2 \%$.

[Insert Table 3 about here]

Column (2) of Table 3 incorporates the first two control variables into the regression: a dummy variable taking the value 1 if the client answers the 10-question version and 0 they take the full 20 questions, and a male dummy variable taking the value 1 when the client is male and zero otherwise. The corresponding parameter estimates are both significant at the $0.1 \%$ level, and have positive and negative signs respectively. In particular, after controlling for age, on average men have a higher $\mathrm{z}$-score than women by around 0.3 standard deviations corresponding to $4.00 \%$ marginal probability of being in the ATR 6 category, which is of relevance since it is a level of risk tolerance one greater than the median ATR of the whole sample, which is equal to five.

\subsection{The Effect of Age on Risk Attitude after Allowing for Risk Capacity}

In the final four columns of Table 3, we additionally include the responses to the three questions that measure the client's financial ability to weather potential losses: capacity, time horizon, liquidity, and an interactive variable that multiplies the three together. We find that all three are highly significant and of economically important magnitudes. In the case of the capacity variable in particular, comparing two clients in the extremes

\footnotetext{
${ }^{27}$ All tables show $y$-standardised coefficients. This method allows us to compare estimates from different models and specifications. See for instance Long and Freese (2006).

${ }^{28}$ We show the total marginal probability of Age including both the linear and squared terms. This allows us to circumvent the issue of possible over-estimation of the distinct of linear and non-linear marginal effects of Age.
} 
of this variable, one with limited capacity and one with large capacity, the probability ${ }^{29}$ increases by $21.56 \%$. We thus argue that while regulators such as the Financial Conduct Authority indicate that risk appetite and risk capacity are separate constructs and should not be conflated and the two are measured entirely separately within DT's system, it is clear that clients take the latter into account when responding to questions about the former to a considerable extent.

The penultimate row of the table indicates that, where only Age and $\mathrm{Age}^{2}$ are included as explanatory variables, a 30-year old would have an ATR score 1.2 units higher than an otherwise identical 80-year old (column (1)), but gender, and capacity-time-liquidity act as mediators in this relationship so that their addition to the regression model reduces the effect of age to around 0.8-1.1 depending on the specification. This equates to a decline of approximately 0.02 units of risk tolerance per year of additional age, evidently a slow rate of reduction.

Table 4 picks up the issue of capacity-time horizon-liquidity that was presented in Table 3 and separates out these variables into all possible combinations. This is useful since the way that they were used in Table 3 implies an embedded restriction that the variable is cardinal when in effect it is merely ordinal, and this restriction is now removed in Table 4 . We find that the results on the effect of these ability to absorb risk measures are intuitive and broadly the same as above. So, for example, for investors with large financial capacity to bear risk, long time horizon and high liquidity (i.e. they would not need to access the investment in a hurry), their z-score is on average more than 1.8 standard deviations greater than the reference category (which is no or limited capacity, short time horizon and low liquidity) and the marginal probability is $20 \%$ higher. $^{30}$

\section{[Insert Table 4 about here]}

Table 5 extends the analysis to consider the effects of employment status on the link between age and risk tolerance. It might be expectable that older investors who continue to work beyond normal retirement age may experience lesser declines in their risk tolerance compared with those who cease work (Rohwedder and Willis, 2010). Several employment categories exist in the DT system, some of which we have merged into: retired, semi-retired, director or partner, temporarily employed or contracted, not working, and employed (but not included in one of the previous categories). The number of observations including employment information is reduced to around 47,000 data points and since the sample is now smaller, we present again the first two regressions from Table 2, columns (1) and (2). As one might expect, compared to the reference category

\footnotetext{
${ }^{29}$ In all tables, we do not report the marginal probability of the interaction term capacity-time-liquidity, but the contribution of each factor conditional on the dependency between them.

${ }^{30}$ Table 4 shows marginal probabilities for the case of an investor more risk tolerant than the average investor (six versus five in ATR scores). On the one hand, the marginal probability of an ATR equal to six does not change when capacity is medium or large. On the other hand, the estimated coefficient summaries the average effects on the z-score when considering all possible ATR scores. Indeed, for higher levels of capacity-time-liquidity, ATR scores greater than six are more probable.
} 
(employed and self-employed investors), semi-retired investors are likely to be less risk-tolerant than the employed, but more risk tolerant than the retired. Clients who hold positions of considerable seniority in their organisations (directors or partners) are the only category probable to be more risk tolerant compared to the others $(1.367 \%)$, their willingness to take financial risks perhaps mirroring those they must take regularly in the course of their jobs. It is also clear that incorporating employment information into the model to explain risk tolerance further reduces the influence of age. In particular, comparing columns (2) and (4), the reduction in ATR score between age 30 and 80 drops from 1.44 without the employment dummies to 1.29 including them.

\section{[Insert Table 5 about here]}

The effect of controlling for marital status when examining the link between ATR and risk tolerance is shown in Table 6. In particular, we include separate dummy variables for clients who are in civil partnerships, and for those who are married, divorced and widowed, with single clients representing the reference category. While the estimates on the latter three are statistically significant, they are of trivial magnitudes. In unreported results where age is excluded from the model, we find that the effect of marital status is much greater, and we therefore conclude that the two are highly related, with marital status going through several life-stages. Similarly, if we examine the effect of including marital status on the numbers reported in the penultimate row of the table, we see that they take almost nothing away from the change in ATR score by age, causing a reduction of only 0.014 between columns (2) and (4).

\section{[Insert Table 6 about here]}

Table 7 adds investment wealth, ${ }^{31}$ reported in the final row of the first panel, to the set of control variables to potentially explain the link between ATR score and age since the literature indicates that risk aversion and wealth are negatively related (Chiappori and Paiella, 2011). As expected, holding all else equal, wealthier investors are likely to be more risk tolerant. For every additional $£ 10,000$ in wealth, there is a marginal probability increase of $0.04 \%$ for moving from an ATR five to six. However, wealth does not mediate in the relationship between ATR score and age, as the parameter estimates on the latter barely alter, and therefore nor does the figure in the penultimate row of the table.

Finally, in Table 8 we show the impact of investment experience in the relationship between age and ATR. As expected, investment experience is also positively related to the probability of higher risk tolerance, and its coefficients are highly significant. The more experienced in investing and knowledgeable about financial

\footnotetext{
${ }^{31}$ We have preliminarily discarded responses where investment wealth is null or missing. We winsorize investment wealth and keep observations within the $1 \%$ and $99 \%$ range percentiles, including threshold values. This filtering methodology is applied by questionnaire type and gender.
} 
literacy the investor is, the more risk tolerant he/she is likely to be. Being an experienced investor increases the marginal probability by $19.2 \%$. Additionally, investment experience does alter the relationship between ATR score and age by more than 0.3 units in the difference between expected ATR for 30-year-old and 80year-old investors.

[Insert Tables 7 and 8 about here]

\subsection{Age and Health}

It is an unfortunate fact of life that old age is usually correlated with an increased chance of poor health. It is expectable that those in a bad health will face future medical expenses, a reduced probability of any employment and possibly reduced life expectancy, all of which would be anticipated to increase risk aversion. ${ }^{32}$ Therefore, two final variables that are incorporated into the demographic data collected by the DT system are on whether the client is in good health and whether the client is a smoker. These variables may also hold additional information on risk tolerance, since we might expect that those who are in poor health would be less risk tolerant while smoking is itself a risky activity from a health perspective and so this may correlate with greater willingness to take financial risks (Ert et al., 2013). Results from including these additional factors in the model are presented in Table 9, and show that health has the expected positive sign (good health = higher risk tolerance) with a marginal probability of more than $2 \%$. Interestingly, incorporating the smoker dummy variable does not influence the self-assessed time horizon estimate at all, indicating that smoking does not reduce the expected investment term of the client or their risk tolerance. If we consider the effects of incorporating these variables on the effect of age in the second-to-last row of the table, we see that being in good health results in a reduction of the effect of increasing age by approximately 0.06 units; the addition of the smoker variable barely affects it, and if anything, it rises.

[Insert Table 9 about here]

\subsection{Cognitive Mediators in the Relationship between ATR and Age}

It would be inappropriate to jump to the immediate conclusion that cognitive decline associated with ageing is the cause of declining risk appetite since several other relevant factors are also typically changing with age, and it may be these related factors that are causing the reduction. First, the percentage of women clients increases substantially with age, primarily due to the greater longevity of the latter (from $39.77 \%$ for women less than 30-year-old to $57.07 \%$ for women in the age 80-100 in DT's database). Second, older people are less likely to be highly educated than the young, given substantial increases in tertiary education participation over

\footnotetext{
${ }^{32}$ Feinstein and Lin (2006) develop a model including poor health and examine its effect upon risk tolerance, while Schurer (2017) finds that the effects of health on risk tolerance are mediated by the positivity of control beliefs.
} 
the past 50 years, and there is evidence that risk tolerance increases with the educational level of the client. Third, older people typically have higher levels of both wealth and investment experience than the youngest, simply because they will have had more time to accumulate them. Fourth, older people are more likely to be divorced or widowed, both of which also affect risk tolerance. Finally, the older a client, the more likely it is that they are retired, and there is also evidence that retirement is correlated with a decline in confidence and cognitive ability separate from a pure age effect, so it might be that risk tolerance for an older client who remains in employment beyond the traditional retirement age does not decline at the same rate as that of a peer who ceases work. There is evidence that the process of retirement itself may hasten the process of cognitive decline with age, since the requirement to keep the mind active in order to be able to function effectively as an employee no longer applies. ${ }^{33}$ Cognitive ability is believed to systematically and positively affect risk tolerance (Benjamin et al., 2013), and it has been suggested that cognitive decline may account for half of all age-related reductions in willingness to take financial risks (Bonsang and Dohmen, 2015). Thus, as well as the cohort, generation and period effects of the decline in risk tolerance with age identified in the previous literature (e.g., Yao, Sharpe and Wang, 2011), we further suggest it could additionally comprise a gender effect, a retirement effect, a marital status effect, and a wealth effect.

Therefore, as we outlined above, by creativity employing information about how the questions are completed in combination, we are able to identify the extent to which each respondent exhibits consistency in decisionmaking. A first way that we can do this is to examine the percentage of middle answers that clients select, broken down by age. Clearly, for most clients, there will be some questions about which they do not feel strongly and thus a 'neither agree nor disagree' is the appropriate response. But if the middle answer is selected too frequently, it is more likely to be indicative of a situation where the client either fails to comprehend the question and thus selects middle answers as a 'safe' default option related to the central tendency bias, or it may represent a refusal to fully engage with the process. Therefore, Table 10 presents the percentage of middle answers selected by clients on average, separated by age bucket, gender, and 10- versus 20 -question versions of the ATR survey. Although we might expect them to choose only $20 \%$ middle answers by chance alone if the responses were all randomly generated, the percentages reported in the table are always much higher but decline monotonically up to age 75:79 (overall and for men) and up to age 70:74 for women. This suggests that older investors are more likely to engage fully with the questions, and are less likely to select a high proportion of middle answers. Interestingly, however, the percentage of middle answers is always higher for the 20-question version, perhaps indicating questionnaire fatigue, and this difference grows with age, suggesting the enhanced resonation with the questions for older investors is partially offset by their reduced ability to remain in such a state for the longer questionnaire.

[Insert Table 10 about here]

\footnotetext{
${ }^{33}$ Ruthirakuhan et al. (2012), for example, show the reverse that remaining physically and mentally active can slow cognitive decline in the elderly.
} 
An alternative way to determine whether rationality in decision-making varies with age is to examine the extent to which the clients select consistent answers across the whole questionnaire. One way to achieve this is to calculate the Cronbach's alpha reliability measure for all clients within an age bucket, which we do separately for the 10- and 20-question versions in Table $11 .{ }^{34}$ Since we employ the same set of questions and calculate the alpha separately for each age grouping, we interpret this as a measure of the extent to which each age group differs in terms of the consistency of their responses across questions. Reliability is a function of the number of questions in the scale, the sample size (which in our case is very large) and the way the questions are answered (see Foreman et al., 1998). According to the psychology literature, risk tolerance actually becomes more stable with age and thus we might expect the Cronbach alpha to be constant or slightly increasing with age (Krosnick and Alwin, 1989). On the other hand, if older clients are suffering from cognitive decline, they are likely to find ATR tests more confusing and difficult to complete coherently. This is particularly the case at the onset of dementia (Thorgrimsen et al., 2003) and thus beyond a certain limit, we might expect reliability as measured by alpha to decline with age. On the other hand, when it's value is too high, it may indicate that the person is answering all questions in the same way- regardless of what the questions are, which would be indicative of lower cognitive ability (or a lower level of care or concentration). In addition, it is possible that a lower observed reliability in older people may simply suggest that the respondent feels the questions to be less relevant to them, and therefore they are not answered in such a consistent way.

We find that systematic change in Cronbach's alpha does occur to a very limited extent from 50-54 onwards. For the 10-question version, it rises slightly from $<30$ to $40-44$ and then remains stable at about 0.82 until age 60 before declining to reach 0.74 by $>80$ years old. For the 20 -question version, the decline with age is barely noticeable, falling from 0.91 when the client is any age from $<30$ to 60 years old, up to 0.89 at $>80$.

[Insert Table 11 about here]

Figure 3 provides further information on the decision-making abilities of younger versus older investors. Panel (a) of the figure plots the percentage of clients selecting at least $60 \%$ middle responses separately by five-year age buckets and also by gender, focusing on the 10-question version of the survey. It is evident that for both women (dashed line with symbols) and men (thick line with no symbols), the percentage of clients triggering the warning falls monotonically with age from around 13 at below 30 years old to 5 at 75-79 before rising slightly thereafter (10 questions). Panel (b) shows the standard deviation of responses, an alternative way of expressing the extent to which clients are engaging with the questions and also whether they are consistent across questions in their responses, now comparing the 10- and 20-question versions. Interestingly, the standard deviation is very flat at around 0.85 across age categories for the 20 -question survey, but it rises noticeably with age from 0.88 at 40:44 to 0.933 at 70:74 for the shorter one. Although our measures cannot be

\footnotetext{
${ }^{34}$ Alpha is usually employed as a measure of the 'reliability' (i.e. consistency) of the items in a survey, and may be defined as an estimate of how closely related the questions are.
} 
considered as constituting any formal tests of cognitive ability, overall, the findings from Tables 10-11 are not suggestive of any age-related declines in the rationality or care with which the ATR questionnaire is completed.

[Insert Figure 3 about here]

Within the 20-question version, there are four occasions where an extremely similar question is being asked in two separate ways ${ }^{35}$ and we would expect that clients who are focused on the task at hand and with strong cognitive skills and memory would then give similar or identical responses in each case. The final Panel (C) of Figure 3 presents the average (across the four instances) of the absolute deviation between each of the two similar questions. ${ }^{36}$ A lower value of this figure would imply a stronger degree of concentration on the part of the client. We find that the average deviation is highest for clients aged 30:35 or below, and there is almost no difference at all in its level, which remains at 0.66 , for clients over 40:44, providing strong evidence that cognitive decline or a lack of focus are unlikely to be the key factors explaining differences in risk tolerance by age.

Table 12 builds on the graphical analysis of Figure 3 to include both the standard deviation of responses and the average deviation of similar questions as additional explanatory variables for the ATR score. We find that the estimated marginal probabilities on both variables are negatively signed and are highly significant, but of moderate magnitude only for the standard deviation of responses. Thus a unit increase in the standard deviation of responses across all questions or in the absolute deviation across similar questions would lead to a decline in marginal probabilities of around $-6.073 \%$ and $-0.845 \%$ respectively. As the penultimate row of the table illustrates, the inclusion of these variables - either individually or in combination - results in either a trivially small decline in the effect of age on ATR or a very slight increase.

Finally, all of the groups of explanatory variables are included together in the results presented in Table 13, so that the effects of each can be compared. ${ }^{37} \mathrm{We}$ find that for this largest model, the ATR spread between $<30$ and +80 year-old investors decreases from 1.657 to 1.080 once we control for all other factors, and the marital status dummies lose their significance, with the remaining variables retaining their signs and significances from the previous regressions.

\footnotetext{
${ }^{35}$ In other words, there are four pairs of questions which refer to similar dimensions of attitude to risk. For instance, the questions 'Compared to the average person, I would say I take more risks' and 'Compared to the average person, I take lower financial risks' are only subtly different.

${ }^{36}$ Note that this analysis is only possible for the approximately $50 \%$ of the sample who answered the longer version of the questionnaire. ${ }^{37}$ Note that this analysis can only be conducted for the sub-sample of clients for which all variables are simultaneously available, which reduces the number of observations significantly, although the remaining sample is still large in absolute terms and the key results of previous tables with larger numbers of data points are preserved. We omit both the absolute deviation of similar questions (only available for the 20 question version) and investment experience (only 403 observations simultaneously available). For brevity, we do not report marginal effects.
} 
[Insert Table 12 and 13 about here]

\section{Conclusions}

This paper has investigated in detail the link between age and attitude to risk using a new database from the UK that is many times larger than any previously available. We have argued that a re-examination of this widely documented phenomenon is highly valuable following changes in retirement patterns, increasing longevity, and the lack of consensus in the existing literature regarding its strength and causes. Using ordered probit regression models, we first confirm the negative relationship between age and risk tolerance documented in existing studies. We find this link to be highly statistically significant but of a modest effect (economic) size.

However, there are likely to be systematic differences in the characteristics of young versus old investors in terms of gender, education level, wealth and health status, and it is important to control for these factors before drawing any firm conclusions on the link between age and attitude to risk. For example, men are almost universally found to be less risk averse than women (Barber and Odean, 2001; Halek and Eisenhauer, 2001; Riley and Chow, 1992); singles tend to be more risk tolerant while married investors are less so, particularly for men (Grable and Roszkowski, 2007; Grable and Jo, 2004), and a higher level of education improves understanding of risks and confidence in taking them and it thus tends to correlate with increased risk tolerance (Grable and Joo, 2004; Sung and Hanna, 1996). We therefore employ a variety of control variables in subsequent regression models and find that they are only partially able to capture the effects of age on ATR, leading us to conclude that there remains a considerable age-related component of the impact that is not linked to the wide array of available demographic and other variables that we employ.

So, what other factors might explain age-related increases in risk aversion? It has been suggested that 'older individuals have difficulty imagining the future' and exhibit 'marked inattention to negative information' (Weierich et al., 2011, p.197), perhaps as part of a wider effort to 'prune negativity from their lives when they perceive time to be more limited' (op. cit., p.200), which may include taking financial risks, as they focus on positive activities. There is also well established body of evidence that the optimality of financial decisionmaking declines with age (e.g., Agarwal et al., 2009), and older investors take longer to adjust their probability estimates in gambles to the true values as more information becomes available (Deakin et al., 2004). They also tend to use simpler heuristics-based approaches to making decisions (Kim et al., 2005; Rafaely et al., 2006). ${ }^{38}$ It has been reported that investors over 70 earn 3-5\% per year lower average risk-adjusted returns (Korniotis and Kumar, 2011). Their increased susceptibility to scams financial fraud is also cited as evidence of poorer decision-making among older adults (Boyle et al. (2012). This is ironic given that they are likely to be

\footnotetext{
${ }^{38}$ Indeed, the primary reason for the introduction of a normal retirement age (of 65) in the US in the early twentieth century was precisely because it was felt that the competence of many older workers, in particular in completing physically demanding tasks, had fallen too low by the time they reached that stage of life (Graebner, 1980).
} 
managing much larger sums of money in their investment accounts due to the longer period that they would have had to accumulate it.

Yao et al. (2011) argue that effects that have been bunched together under the age heading are actually a composite of several factors: 'what was attributed to an 'age effect' may be due to a decrease of investment horizon and depreciation of human capital as people age...' (Yao et al., 2011, p.872). We are able to formally test this conjecture, and we indeed observe that capacity to bear financial losses and investment horizon decline with age since older clients may consider themselves to have shorter time periods available to make up any temporary losses in asset values (Jianakoplos and Bernasek, 2006). However, we demonstrate that these variables are insufficient to explain the age-ATR link.

When controlling for age and a host of other factors including wealth, Grinblatt et al. (2011) find a high positive relationship between IQ and stock market investment as well as better balanced and more efficient portfolios. Extending this result to our context, it may be that the elderly eschew risky asset allocations not because they cannot tolerate risk per se ${ }^{39}$ but rather because in the financial context they are disproportionately more likely to make bad investment decisions and so face a less attractive risk-return trade-off (poorer diversification and more volatility) than the young; a falling confidence in their own ability may also play a factor (see Yang, 2013). ${ }^{40}$ Westbrook et al. (2012) argue that risk aversion is a natural response to a lack of knowledge about the optimal strategy required to achieve a more desirable outcome. They show that risk aversion among the young declines to a greater extent with clear instruction and practice in the task than is the case with older adults, which is attributed to diminished cognitive resources and a reduced ability to keep in check the effect of kneejerk, automatic responses within the latter group. It is challenging to test this proposition with real data (as opposed to an artificial experimental or survey setting), and while we find that more inconsistency in answers within the ATR questionnaire is linked with more risk aversion as the theory would predict, we are not able to uncover any evidence that this explains age-related declines in risk tolerance.

A further factor that is likely to be important in practice, but which we cannot observe using our (or any other) database, is the extent to which each older investor is saving to cover their own needs or with the intention to leave a legacy. This is key since there is a strong indication in the literature that people differ in the way that they make decisions dependent upon whether they are making choices on behalf of themselves or for others, with their willingness to take risks being greater in the latter cases (Charkravarty et al., 2011; Andersson et al., 2013), particularly in the domain of losses (Pahlke et al., 2012). This relates to a lesser arousal from negative outcomes when choices are made on others' behalves (Sokol-Hessner et al., 2013).

\footnotetext{
${ }^{39}$ Indeed, there is evidence that the elderly are more risk-seeking than the young in other (non-financial) contexts (Denburg et al., 2005).

${ }^{40}$ This effect may also explain the interesting observation that older investors may be more inclined to focus on their expected reactions to positive future events than their reactions to losses (Samanez-Larkin et al., 2007; Weirich et al., 2011), and yet this positivity would usually be expected to lead them to be willing to take more, not less, risk.
} 
Expanding the purview beyond a consideration of age specifically, a further important finding from our analysis is the overall lack of explanatory power from the broad array of demographic and other factors that we employ. This is strongly suggestive that attitude to financial risk varies from person-to-person as a result of innate personality traits in ways that are unpredictable based on observable variables, implying that it would be wholly inappropriate to classify people into 'types' with a presumption that their attitude to risk can be determined accordingly. From a regulatory perspective, we suggest that the current approach, where a financial advisor uses a formal ATR questionnaire supplemented by an extensive, broader fact find ('getting to know your client') to ascertain their needs, expectations and aspirations, is entirely the right one.

The relatively lower risk tolerance among the elderly, combined with an ageing population (caused by both increased longevity and declining birth rates) has potentially profound implications for investment markets and the cost of capital for firms and projects. Given the significant, albeit slow, declines in risk tolerance that occur with age - whatever the reason - the demand for risky assets may decline with more money chasing ever declining yields on safer assets that barely provide a positive real return. This, combined with the gradual move from defined benefit pension schemes (where the plan sponsor or fund manager determines the asset allocation and can afford to invest in illiquid, risky assets) to defined contribution schemes (where investors typically have some latitude to determine the allocation themselves), may starve risky projects such as those in infrastructure, of a vital supply of funding. This could potentially entail severely detrimental effects for economic growth in the long-term and further research is required to investigate the knock-on impacts of the investment choices of the growing number of older investors who in total control large amounts of wealth. 


\section{References}

Agarwal, S., Driscoll, J. C., Gabaix, X., and Laibson, D. (2009) The age of reason: Financial decisions over the life cycle and implications for regulation Brookings Papers on Economic Activity, 2009(2), 51-117.

Alan, S., Baydar, N., Boneva, T., Crossley, T. F., \& Ertac, S. (2017). Transmission of risk preferences from mothers to daughters. Journal of Economic Behavior \& Organization, 134, 60-77.

Albert, S.M. and Duffy, J. (2012) Differences in risk aversion between younger and older adults Neuroscience and Neuroeconomics 1, 3-9.

Andersson, O., Tyran, J-R, Wengerström, E. and Holm, H.J. (2013b) Deciding for others reduces loss aversion IFN Working Paper 976, Research Institute of Industrial Economics, Stockholm, Sweden.

Antolin, P. (2010) Private pensions and the financial crisis: How to ensure adequate retirement income from DC pension plans. OECD Publishing.

Bailey, J.J., Nofsinger, J.R. and O'neill, M. (2003). A review of major influences on employee retirement investment decisions Journal of Financial Services Research 23(2), 149-165.

Barber, B. and Odean, T. (2001) Boys will be boys: gender, overconfidence and common stock investment Quarterly Journal of Economics 116(1), 261-292.

Bateman, H., Islam, T., Louviere, J., Satchell, S., and Thorp, S. (2011) Retirement investor risk tolerance in tranquil and crisis periods: experimental survey evidence. Journal of Behavioral Finance 12(4), 201-218.

Bellante, D. and Green, C.A. (2004) Relative risk aversion among the elderly Review of Financial Economics $13,269-281$.

Benjamin, D.J., Brown, S.A., and Shapiro, J.M. (2013) Who is 'behavioral'? Cognitive ability and anomalous preferences Journal of the European Economic Association 11(6), 1231-1255.

Bluethgen, R., Gintschel, A., Hackethal, A. and Müller, A. (2008) Financial advice and individual investors' portfolios. Working paper, European Business School, Oestrich-Winkel.

Bommier, A. and Rochet, J.C. (2006) Risk aversion and planning horizons Journal of the European Economic Association 4(4), 708-734.

Bonsang, E., \& Dohmen, T. (2015). Risk attitude and cognitive aging. Journal of Economic Behavior \& Organization, 112, 112-126.

Browning, C. and Finke, M. (2015) Cognitive ability and the stock reallocations of retirees during the great recession Journal of Consumer Affairs 49(2), 356-375.

Bucciol, A., and Miniaci, R. (2011) Household portfolios and implicit risk preference Review of Economics and Statistics 93(4), 1235-1250. 
Camerer, C.F. and Hogarth, R.M. (1999) The effects of financial incentives in experiments: A review and capital-labor production framework Journal of Risk and Uncertainty 19, 7-42.

Chakravarty, S., Harrison, G., Haruvy, E.E. and Ruström, E. (2011) Are you risk averse over other peoples' money? Southern Economic Journal 77(4), 901-913.

Chiappori, P.-A., Paiella, M. (2011) Relative risk aversion is constant: Evidence from panel data Journal of the European Economic Association 9(6), 1021-1052

Clark, G.L. and Strauss, K. (2008) Individual pension-related risk propensities: the effect of sociodemographic characteristics and a spousal entitlement on risk attitudes Ageing and Society 28, 847-874.

Deakin, J., Aitken, M., Robbins, T. and Sahakian, B.J. (2004) Risk taking during decision-making in normal volunteers changes with age Journal of the International Neuropsychological Society 10, 590-598.

Denburg, N.L., Tranel, D., and Bechara, A. (2005) The ability to decide advantageously declines prematurely in some older persons Neuropsychologia 43, 1099-1106.

Dohmen, T., Falk, A., Huffman, D., Sunde, U., Schupp, J., and Wagner, G. G. (2011) Individual risk attitudes: Measurement, determinants, and behavioral consequences Journal of the European Economic Association, 9(3), 522-550.

Ert E., Yechiam E. and Arshavsky O. (2013) Smokers' Decision Making: More than Mere Risk Taking PLoS ONE 8(7), 1-7.

Faff, R., Hallahan, T. and McKenzie, M. (2011) Women and risk tolerance in an aging world International Journal of Accounting and Information Management 19(2), 100-117.

Faff, R., Mulino, D. and Chai, D. (2008) On the linkage between financial risk tolerance and risk aversion Journal of Financial Research 31(1), 1-23.

Fagereng, A., Gottlieb, C. and Guiso, L. (2017) Asset market participation and portfolio choice over the lifecycle Journal of Finance forthcoming.

Fein, G., McGillivray, S. and Finn, P. (2007) Older adults make less advantageous decisions than younger adults: cognitive and psychological correlates Journal of the International Neuropsychological Society 13, 480-489.

Feinstein, J.S. and Lin, C-Y. (2006) Elderly asset management Working Paper, Yale School of Management.

Filbeck, G., Hatfield, P. and Horvath, P. (2005) Risk aversion and personality type Journal of Behavioral Finance 6(4), 170-180. 
Forman, S., Money, A., \& Page, M. J. (1998). How reliable is reliable? A note on the estimation of Cronbach alpha. In Proceedings of the International Management Conference, Cape Town, South Africa, May 1998 (pp. 1-26).

Friesen, G. and Sapp, T. (2007) Mutual fund flows and investor returns: an empirical evaluation of fund investor timing ability Journal of Banking and Finance 31, 2796-2816.

Gerrans, P., Faff, R. and Hartnett, N. (2015) Individual financial risk tolerance and the global financial crisis Accounting and Finance 55, 165-185.

Gilbert, D.T. and Wilson, T.D. (2009) Why the brain talks to itself: sources of error in emotional prediction Philosophical Transactions of the Royal Society B 364, 1335-1341.

Grable, J.E. (2000) Financial risk tolerance and additional factors that affect risk taking in everyday money matters Journal of Business and Psychology 14(4), 25-63.

Grable, J.E. and Joo, S. (2004) Environmental and biopsychcosocial factors associated with risk tolerance Financial Counseling and Planning 15(1), 73-82.

Grable, J.E., Lytton, R.H., O’Neill, B., Joo, S.H. and Klock, D. (2006) Risk tolerance, projection bias, vividness and equity prices Journal of Investing Summer, 68-74.

Grable, J.E. and Roszkowski, M.J. (2007) Self-assessments of risk tolerance by women and men Psychological Reports 100, 795-802.

Graebner, W. (1980) History of Retirement Yale University Press, New Haven, Conneticut.

Grinblatt, M., Keloharju, M. and Linnainmaa, J. (2011) IQ and stock market participation Journal of Finance 66(6), 2121-2164.

Guiso, L., Sapienza, P. and Zingales, L. (2017) Time varying risk aversion Journal of Finance forthcoming.

Halek, M. and Eisenhauer, J.G. (2001) Demography of risk aversion Journal of Risk and Insurance 68(1), 124.

Henninger, D.E., Maden, D.J. and Huettel, S.A. (2010) Processing speed and memory mediate age-related differences in decision-making Psychology and Aging 25(2), 262-270.

Hess, T.M. (2015) A prospect theory-based evaluation of dual-process influences on aging and decisionmaking: support for a contextual perspective in Hess, T.M., Strough, J. and Loeckenhoff, C.E. (eds.) Aging and Decision-Making: Empirical and Applied Perspectives, Elsevier, New York.

Holt, C.A. and Laury, S.K. (2002) Risk aversion and incentive effects American Economic Review 92(5), 1644-1655. 
Hunt, S., Stewart, N. and Zaliauskas, R. (2015) Two plus two makes five? Survey evidence that investors overvalue structured deposits. FCA Occasional Paper No. 9.

Jianakoplos, N.A. and Bernasek, A. (2006) Financial risk taking by age and birth cohort Southern Economic Journal 72(4), 981-1001.

James, B.D., Boyle, P.A., Yu, L., Han, S.D. and Bennett, D.A. (2015) Cognitive decline is associated with risk aversion and temporal discounting in older adults without dementia Plos One 10(4), 1-12.

Kara, A. and Moyneux, P. (2017) Household Access to Mortgages in the UK Journal of Financial Services Research, forthcoming.

Kim, S., Goldstein, D., Hasher, L. and Zacks, R.T. (2005) Framing effects in younger and older adults Journal of Gerontology: Series B: Psychological Science 60, 215-218.

Korniotis, G.M. and Kumar, A. (2011) Do older investors make better investment decisions? Review of Economics and Statistics 93(1), 244-265.

Koscielniak, M., Rydzewska, K. and Sedek, G. (2016) Effects of age and initial risk perception on balloon analog risk task: the mediating role of processing speed and need for cognitive closure Frontiers in Psychology 7, 1-13.

Krosnick, J.A. and Alwin, D.F. (1989) Ageing and susceptibility to attitude change Journal of Personality and Social Psychology, 57(3), 416-425.

Kurglanski, A. and Webster, D. (1996) Motivated closing of the mind: 'seizing' and 'freezing' Psychological Review 2, 263-283.

Kumar, A. (2009) Who gambles in the stock market? Journal of Finance, 64(4), 1889-1933.

Kurnianingsih, Y.A., Sim, S.K., Chee, M.W.L. and Mullette-Gillman, O.A. (2015) Aging and loss decisionmaking: increased risk aversion and decreased use of maximising information, with correlated rationality and value maximization Frontiers in Human Neuroscience 9, 1-12.

Larkin C., Lucey B. M. and Mulholland M. (2013). Risk tolerance and demographic characteristics: Preliminary Irish evidence Financial Services Review, 22(1), 77-91.

Long, J. S., and Freese, J. (2006). Regression models for categorical dependent variables using Stata. Stata press.

McCrae, R. and Costa, P. (1994) The stability of personality: observations and evaluations Current Directions in Psychological Science 3, 173-175.

McInish, T.H. (1982) Individual investors and risk taking Journal of Economic Psychology 2(2), 125-136. 
Mein, G., Martikainen, P., Stansfeld, S. A., Brunner, E. J., Fuhrer, R., \& Marmot, M. G. (2000). Predictors of early retirement in British civil servants. Age and Ageing, 29(6), 529-536.

Morin, R.A. and Suarez, A.F. (1983) Risk aversion revisited Journal of Finance 38(4), 1201-1216.

Pahlke, J., Strasser, S. and Vieider, F.M. (2012) Responsibility effects in decision making under risk $W Z B$ Discussion Paper No. SP II 2012-402, Leibniz Information Centre.

Park, D.C. and Reuter-Lorenz, P. (2009) The adaptive brain: aging and neurocognitive scaffolding Annual Review of Psychology 60, 173-196.

Patacchini, E., \& Rainone, E. (2017). Social Ties and the Demand for Financial Services. Journal of Financial Services Research forthcoming.

Rafaely, V., Dror, I.W. and Remington, B. (2006) Information selectivity in decision making by younger and older adults International Journal of Psychology 41, 117-131.

Rajah, M.N., Languay, R. and Valiquette, L. (2010) Age-related changes in prefrontal cortex acrivity are associated with behavioural deficits in both temporal and spatial context memory retrieval in older adults Cortex 46, 535-549.

Riley, W.B. and Chow, K.V. (1992) Asset allocation and individual risk aversion Financial Analysts Journal 48(6), 32-37.

Rohwedder, S., \& Willis, R. J. (2010). Mental retirement. Journal of Economic Perspectives, 24(1), 119-138.

Roszkowski, M.J. and Davey, G. (2010) Risk perception and risk tolerance changes attributable to the 2008 economic crisis: a subtle but critical difference Journal of Financial Services Professionals 64(4), 42-53.

Ruthirakuhan, M., Luedke, A.C., Tam, A., Goel, A., Kurji, A. and Garcia, A. (2012) Use of Physical and Intellectual Activities and Socialization in the Management of Cognitive Decline of Aging and in Dementia: A Review Journal of Aging Research, 2012, 1-14.

Rypma, B., Prabhakaran, V. Desmond, J.E. and Gabrieli, J.D. (2001) Age differences in prefrontal cortical activity in working memory Psychology and Aging 16(3), 371-384.

Salthouse, T.A. (1990) Working memory as a processing resource in cognitive aging Developmental Review $10,101-124$.

Salthouse, T.A. (2001) Structural models of the relation between age and measures of cognitive functioning Intelligence 29, 93-115.

Samanez-Larkin, G.R, Gibbs, G.R., Gibbs, S.E.B., Khanna, K., Nielsen, L., Carstensen, L.L. and Knutson, B. (2007) Anticipation of monetary gain but not loss in older adults Nature Neuroscience 10, 787-791. 
Schurer, S. (2017). Bouncing back from health shocks: Locus of control and labor supply. Journal of Economic Behavior \& Organization, 133, 1-20.

Schurer, S. (2015). Lifecycle patterns in the socioeconomic gradient of risk preferences. Journal of Economic Behavior \& Organization, 119, 482-495.

Shapira, Z. and Venezia, I. (2001) Patterns of behavior of professionally managed and independent investors Journal of Banking and Finance 25(8), 1573-1587.

Smith, V.L. and Walker, J.M. (1993) Monetary rewards and decision costs in experimental economics Economic Inquiry 31, 245-261.

Sokol-Hessner, P., Camerer, C.F. and Phelps, E.A. (2013) Emotion regulation reduces loss aversion and decreases amygdala responses to losses Social Cognitive and Effective Neuroscience 8(3), 341-350.

Sung, J. and Hanna, S.D. (1996) Factors related to risk tolerance Financial Counseling and Planning 7(1), 1120.

Tausch, F. and Zumbuehl, M. (2016) Stability of risk attitudes and media coverage of economic news Working Paper, Max Plank Institute for Research on Collective Goods, Bonn.

Thorgrimsen, L, Selwood, A., Spector, A, Royan, L, de Madariaga Lopez, M., Woods, R. T. and Orrell, M. (2003) Whose quality of life is it anyway? The validity and reliability of the quality of life-Alzheimer's disease (QoL-AD) scale Alzheimer Disease and Associated Disorders 17(4), 201-208.

Tun, P.A., Wingfield, A.R., Merri, J. and Blanchard, L. (1998) Response latencies for false memories: Gistbased processes in normal aging Psychology and Aging 13, 230-241.

Verhaeghen, P. and Cerella, J. (2002) Aging, executive function and attention: a review of metanalyses Neuroscience and Biobehavioral Reviews 26, 849-856.

Walker, A. (2002). A strategy for active ageing. International social security review, 55(1), 121-139.

Wang, C. and Hana, S.D. (1997) Does risk tolerance decrease with age? Financial Counseling and Planning $8(2), 27-31$.

Weber, M., Weber, E.U. and Nosić, A. (2013) Who takes risks when and why: determinants of changes in investor risk taking Review of Finance 17, 847-883.

Weierich, M.R., Kensinger, E.A., Munnell, A.H., Sass, S.A., Dickerson, B.C., Wright, C.I. and Barrett, L.F. (2011) Older and wiser? An affective science perspective on age-related challenges in financial decisionmaking SCAN 6, 195-206.

Westbrook, A., Martins, B.S., Yarkoni, T. and Braver, T.S. (2012) Strategic insight and age-related goalneglect influence risky decision-making Frontiers in Neuroscience 6, 1-13. 
Yang, A. S. (2013) Decision making for individual investors: A measurement of latent difficulties Journal of Financial Services Research 44(3), 303-329.

Yao, R., Hanna, S.D. and Lindamood, S. (2004) Changes in financial risk tolerance, 1983-2001 Financial Services Review 13, 249-266.

Yao, R., Sharpe, D.L. and Wang, F. (2011) Decomposing the age effect on risk tolerance Journal of Socioeconomics 40(6), 879-887. 


\section{$\underline{\text { Figures and Tables }}$}

Figure 1: Attitude to Risk

\section{Panel A: ATR and number of Clients over time}

This figure shows the monthly average attitude to risk (measured in scores from 1 to 10) and the total monthly number of clients in Panel A, and the estimated attitude to risk (Calculated ATR), measured in scores from 1 to 10, with 95\% confidence bounds in Panel B over the period from 1 January 2011 to 31 August 2016. The model estimated in Panel $\mathrm{B}$ is an ordered probit with robust standard errors and time fixed effects (year).

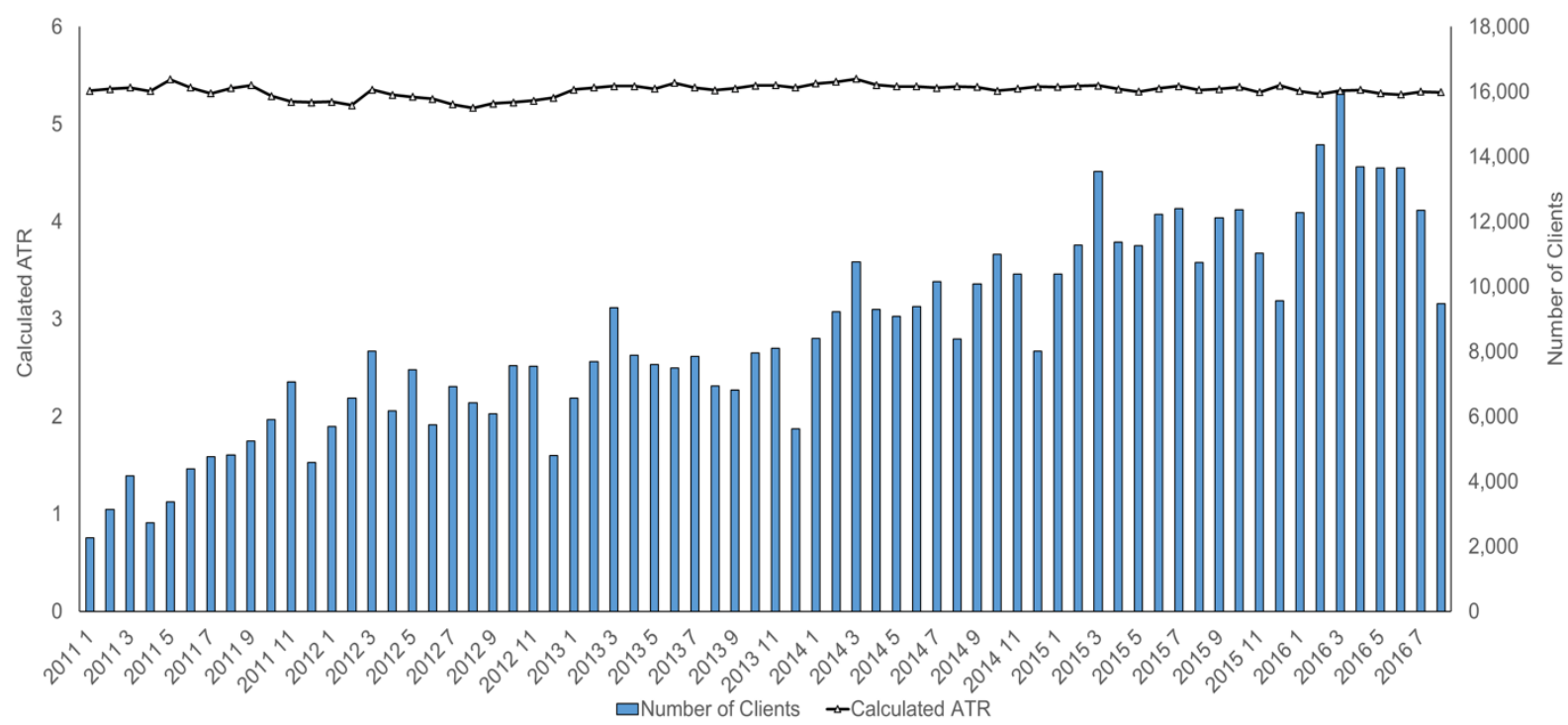

Panel B: Calculated ATR Separated by Age and Gender

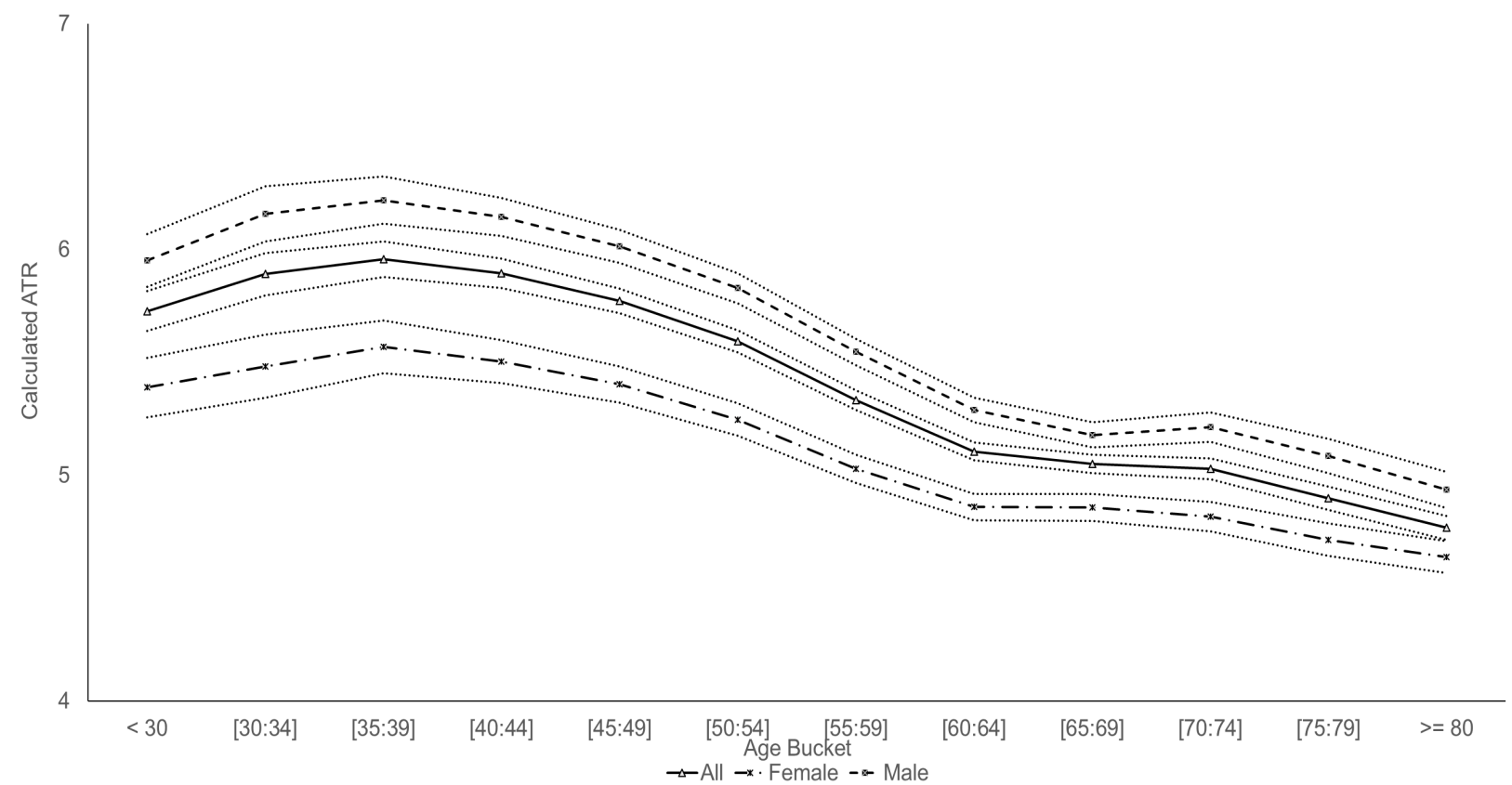




\section{Figure 2: Estimated Probability Distribution of Attitude to Risk by Age buckets}

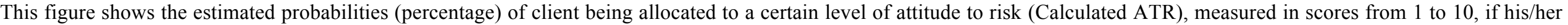

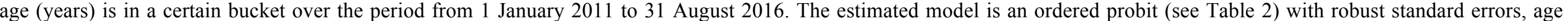
buckets' dummies and time fixed effects (year). All probabilities are significant at the $1 \%$ significance level

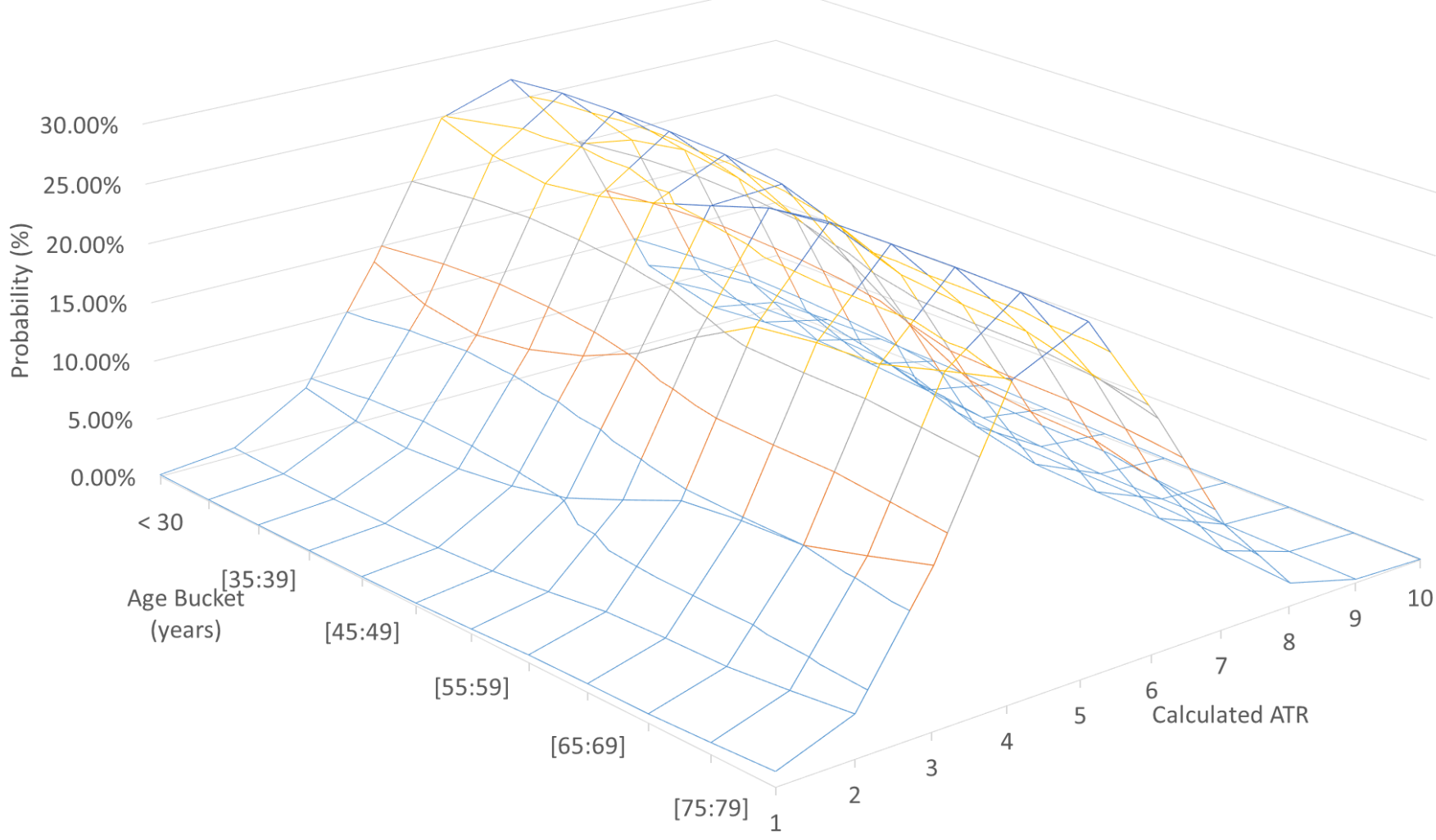

$\square 0.00 \%-5.00 \% \quad \square 5.00 \%-10.00 \% \quad \square 10.00 \%-15.00 \% \quad \square 15.00 \%-20.00 \% \quad \square 20.00 \%-25.00 \% \quad \square 25.00 \%-30.00 \%$ 


\section{Table 1: Summary statistics and Spearman's correlation matrix of attitude to risk and age}

This table reports summary statistics and correlation matrix of attitude to risk and age over the sample period 1 January 2011 to 31 August 2016. Calculated ATR is the attitude to risk of the investor (scores from 1 to 10, where 10 indicates the highest tolerance risk level and 1 the lowest level). Age (measured in years) is the investor's age. Capacity is the investor's ability to bear financial losses. Time is the investor's time horizon of investments. Liquidity is the investor's urgency to access investments. Capacity, Time and Liquidity are all measured as score variables from 0 to 2, where 0 indicates a low level and 2 a high level. Panel A presents the summary statistics of attitude to risk by age bucket; Panel B reports the summary statistics of age (years); Panel C reports the Spearman's correlation matrix of attitude to risk and age with capacity, timeframe and liquidity. $* * *$ and $* * *$ indicate significance at the $10 \%, 5 \%$ and $1 \%$ levels respectively.

\begin{tabular}{|c|c|c|c|c|c|c|c|c|c|}
\hline \multicolumn{10}{|c|}{ Panel A: Summary Statistics for Calculated ATR } \\
\hline \multirow{2}{*}{ Age Bucket } & \multicolumn{3}{|c|}{$\begin{array}{c}\text { Number of completed } \\
\text { questionnaires }\end{array}$} & \multirow{2}{*}{$\frac{\text { Average }}{\text { All }}$} & \multirow[b]{2}{*}{ Female } & \multirow[b]{2}{*}{ Male } & \multirow[b]{2}{*}{ Difference } & \multirow{2}{*}{$\frac{\text { Median }}{\text { All }}$} & \multirow{2}{*}{$\begin{array}{c}\begin{array}{c}\text { Standard } \\
\text { Deviation }\end{array} \\
\text { All }\end{array}$} \\
\hline & All & Female & Male & & & & & & \\
\hline$<30$ & 14,725 & 5,856 & 8,869 & 5.717 & 5.376 & 5.943 & $-0.567 * * *$ & 6 & 1.500 \\
\hline$[30: 34]$ & 13,716 & 5,458 & 8,258 & 5.717 & 5.466 & 6.145 & $-0.680 * * *$ & 6 & 1.477 \\
\hline [35:39] & 21,601 & 8,649 & 12,952 & 5.946 & 5.553 & 6.209 & $-0.656^{* * *}$ & 6 & 1.465 \\
\hline$[40: 44]$ & 38,956 & 15,253 & 23,703 & 5.884 & 5.493 & 6.135 & $-0.643 * * *$ & 6 & 1.482 \\
\hline [45:49] & 58,388 & 23,049 & 35,339 & 5.770 & 5.400 & 6.011 & $-0.612 * * *$ & 6 & 1.463 \\
\hline$[50: 54]$ & 72,278 & 29,229 & 43,049 & 5.593 & 5.248 & 5.827 & $-0.579 * * *$ & 6 & 1.466 \\
\hline [55:59] & 89,051 & 36,648 & 52,403 & 5.336 & 5.033 & 5.548 & $-0.515^{* * *}$ & 5 & 1.448 \\
\hline [60:64] & 91,360 & 38,942 & 52,418 & 5.108 & 4.861 & 5.291 & $-0.430 * * *$ & 5 & 1.409 \\
\hline [65:69] & 81,855 & 32,704 & 49,151 & 5.054 & 4.861 & 5.182 & $-0.322 * * *$ & 5 & 1.368 \\
\hline [70:74] & 45,188 & 21,175 & 24,013 & 5.034 & 4.822 & 5.220 & $-0.398 * * *$ & 5 & 1.298 \\
\hline$[75: 79]$ & 27,354 & 13,873 & 13,481 & 4.901 & 4.719 & 5.090 & $-0.371 * * *$ & 5 & 1.285 \\
\hline$>=80$ & 24,910 & 14,217 & 10,693 & 4.771 & 4.643 & 4.941 & $-0.298^{* * *}$ & 5 & 1.270 \\
\hline All ages & 579,382 & 245,053 & 334,329 & 5.350 & 5.049 & 5.570 & $-0.521 * * *$ & 5 & 1.456 \\
\hline
\end{tabular}

\begin{tabular}{cccccc}
\hline \multicolumn{2}{l}{ Panel B: Summary Statistics for Age } & \multicolumn{1}{l}{} \\
\hline Age & $10 Q$ & $20 Q$ & Female & Male & All \\
\hline Mean & 57.544 & 57.721 & 58.631 & 56.911 & 57.638 \\
Median & 58.000 & 59.000 & 59.000 & 58.000 & 58.000 \\
Standard Deviation & 13.090 & 12.974 & 13.424 & 12.681 & 13.028 \\
Minimum & 18.000 & 18.000 & 18.000 & 18.000 & 18.000 \\
Maximum & 100.000 & 100.000 & 100.000 & 100.000 & 100.000 \\
No. of Observations & 270,255 & 309,127 & 245,053 & 334,329 & 579,382 \\
\hline
\end{tabular}

\begin{tabular}{ccccc}
\hline Panel C: Spearman's Correlation & & & \\
\hline Variables & Calculated ATR & Age & Capacity & Timeframe \\
\hline Age & $-0.2306^{* * *}$ & & & \\
Capacity & $0.3957^{* * *}$ & $-0.0494^{* *}$ & & \\
Timeframe & $0.1932^{* * *}$ & $-0.3911^{* * *}$ & $0.1788^{* * *}$ & \\
Liquidity & $0.090^{* * *}$ & $-0.003^{* * *}$ & $0.1773^{* * *}$ & $0.1207^{* * *}$ \\
\hline
\end{tabular}




\section{Table 2: Estimated Attitude to Risk by Age bucket and Probabilities}

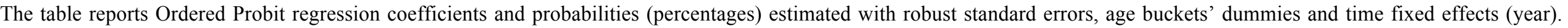
Period: 1 January $2011-31$ August 2016.*,** and *** indicate significance at the $10 \%, 5 \%$ and $1 \%$ levels respectively. All probabilities are significant at the $1 \%$ level.

\begin{tabular}{|c|c|c|c|c|c|c|c|c|c|c|c|c|c|}
\hline \multirow{2}{*}{ Dep. Var. Calculated ATR } & \multicolumn{2}{|c|}{ Ordered Probit } & \multicolumn{10}{|c|}{ Probabilities by Calculated ATR } & \multirow{2}{*}{ Expected ATP } \\
\hline & Coef. & $\mathrm{z}$ & 1 & 2 & 3 & 4 & 5 & 6 & 7 & 8 & 9 & 10 & \\
\hline \multicolumn{14}{|l|}{ Ind. Variables: } \\
\hline$<30$ & - & - & $0.16 \%$ & $0.73 \%$ & $4.29 \%$ & $13.79 \%$ & $24.87 \%$ & $26.87 \%$ & $19.77 \%$ & $7.21 \%$ & $1.73 \%$ & $0.59 \%$ & 5.727 \\
\hline$[30: 34]$ & $0.116^{* * *}$ & 9.11 & $0.11 \%$ & $0.53 \%$ & $3.40 \%$ & $11.89 \%$ & $23.30 \%$ & $27.28 \%$ & $21.79 \%$ & $8.64 \%$ & $2.23 \%$ & $0.82 \%$ & 5.891 \\
\hline$[35: 39]$ & $0.166^{* * *}$ & 14.49 & $0.09 \%$ & $0.47 \%$ & $3.08 \%$ & $11.15 \%$ & $22.60 \%$ & $27.35 \%$ & $22.59 \%$ & $9.27 \%$ & $2.46 \%$ & $0.94 \%$ & 5.958 \\
\hline$[40: 44]$ & $0.124 * * *$ & 11.83 & $0.11 \%$ & $0.53 \%$ & $3.39 \%$ & $11.85 \%$ & $23.26 \%$ & $27.29 \%$ & $21.83 \%$ & $8.68 \%$ & $2.24 \%$ & $0.83 \%$ & 5.894 \\
\hline [45:49] & $0.038 * * *$ & 3.84 & $0.14 \%$ & $0.67 \%$ & $4.03 \%$ & $13.25 \%$ & $24.45 \%$ & $27.02 \%$ & $20.34 \%$ & $7.60 \%$ & $1.86 \%$ & $0.65 \%$ & 5.773 \\
\hline$[50: 54]$ & $-0.096^{* * *}$ & -9.81 & $0.22 \%$ & $0.94 \%$ & $5.15 \%$ & $15.41 \%$ & $25.97 \%$ & $26.27 \%$ & $18.06 \%$ & $6.16 \%$ & $1.39 \%$ & $0.45 \%$ & 5.593 \\
\hline$[55: 59]$ & $-0.287 * * *$ & -29.87 & $0.38 \%$ & $1.47 \%$ & $7.12 \%$ & $18.65 \%$ & $27.54 \%$ & $24.50 \%$ & $14.78 \%$ & $4.41 \%$ & $0.89 \%$ & $0.25 \%$ & 5.333 \\
\hline$[60: 64]$ & $-0.453 * * *$ & -47.34 & $0.62 \%$ & $2.12 \%$ & $9.20 \%$ & $21.43 \%$ & $28.20 \%$ & $22.42 \%$ & $12.07 \%$ & $3.21 \%$ & $0.58 \%$ & $0.15 \%$ & 5.106 \\
\hline$[65: 69]$ & $-0.493^{* * *}$ & -51.26 & $0.69 \%$ & $2.31 \%$ & $9.76 \%$ & $22.09 \%$ & $28.25 \%$ & $21.85 \%$ & $11.44 \%$ & $2.95 \%$ & $0.52 \%$ & $0.13 \%$ & 5.051 \\
\hline$[70: 74]$ & $-0.510 * * *$ & -51.02 & $0.72 \%$ & $2.39 \%$ & $9.99 \%$ & $22.35 \%$ & $28.26 \%$ & $21.61 \%$ & $11.19 \%$ & $2.85 \%$ & $0.50 \%$ & $0.12 \%$ & 5.028 \\
\hline [75:79] & $-0.601 * * *$ & -56.75 & $0.93 \%$ & $2.90 \%$ & $11.37 \%$ & $23.80 \%$ & $28.17 \%$ & $20.21 \%$ & $9.80 \%$ & $2.34 \%$ & $0.39 \%$ & $0.09 \%$ & 4.899 \\
\hline$>=80$ & $-0.696^{* * *}$ & -64.93 & $1.20 \%$ & $3.50 \%$ & $12.87 \%$ & $25.15 \%$ & $27.83 \%$ & $18.71 \%$ & $8.49 \%$ & $1.89 \%$ & $0.29 \%$ & $0.07 \%$ & 4.767 \\
\hline Observations & 579,382 & & & & & & & & & & & & \\
\hline Time FE (Year) & $\mathrm{Y}$ & & & & & & & & & & & & \\
\hline$\Delta$ Probabilities $($ or ATR) $/$ Age $[<30 ;>=80]$ & - & & $-1.04 \%$ & $-2.76 \%$ & $-8.57 \%$ & $-11.36 \%$ & $-2.97 \%$ & $8.16 \%$ & $11.27 \%$ & $5.32 \%$ & $1.43 \%$ & $0.53 \%$ & 0.960 \\
\hline Pseudo $\mathrm{R}^{2}$ & 0.0204 & & & & & & & & & & & & \\
\hline
\end{tabular}




\section{Table 3: Attitude to Risk and Age - Ordered Probit regressions results}

Order Probit regressions estimated with robust standard errors and time fixed effects (years). Period: 1 January 2011 - 31 August 2016. Other variable definitions and measurements are explained in the notes to Table 1. $\mathbf{A g e}^{2}$ is measured in years / 1,000. 10 Question version is a dummy variable which equals one if the questionnaire is the 10 question version, and zero otherwise. Male is a binary variable which equals one if the investor's gender is male, and zero otherwise. Z-tests are reported in parentheses. Marginal effects are reported in percentages. $*, * *$ and $* * *$ indicate significance at the $10 \%, 5 \%$ and $1 \%$ levels respectively.

\begin{tabular}{|c|c|c|c|c|c|c|c|}
\hline Dep. Var. Calculated ATR & (1) & (2) & (3) & (4) & (5) & (6) & (7) \\
\hline \multicolumn{8}{|l|}{ Ind. Variables: } \\
\hline \multirow[t]{3}{*}{ Age } & $-0.0120 * * *$ & $-0.0156 * * *$ & $-0.0026 * * *$ & $-0.0101 * * *$ & $-0.0140 * * *$ & $-0.0011^{*}$ & -0.0002 \\
\hline & $(-16.91)$ & $(-22.22)$ & $(-4.06)$ & $(-14.61)$ & $(-20.14)$ & $(-1.72)$ & $(-0.39)$ \\
\hline & $-0.201 \%$ & $-0.204 \%$ & $-0.234 \%$ & $-0.162 \%$ & $-0.208 \%$ & $-0.172 \%$ & $-0.211 \%$ \\
\hline \multirow[t]{3}{*}{$\operatorname{Age}^{2}$} & $-0.0501 * * *$ & $-0.0113^{*}$ & $-0.1132 * * *$ & $-0.0261 * * *$ & $-0.0253 * * *$ & $-0.0922 * * *$ & $-0.1194 * * *$ \\
\hline & $(-8.21)$ & $(-1.88)$ & $(-20.59)$ & $(-4.43)$ & $(-4.25)$ & $(-16.41)$ & $(-21.85)$ \\
\hline & - & - & - & - & - & - & - \\
\hline \multirow[t]{3}{*}{10 Question version } & & $-0.2352 * * *$ & $-0.1882 * * *$ & $-0.2357 * * *$ & $-0.2313 * * *$ & $-0.2074 * * *$ & $-0.1892 * * *$ \\
\hline & & $(-82.12)$ & $(-71.66)$ & $(-82.98)$ & $(-81.25)$ & $(-76.49)$ & $(-72.25)$ \\
\hline & & $-2.851 \%$ & $-2.801 \%$ & $-2.915 \%$ & $-2.840 \%$ & $-3.017 \%$ & $-2.832 \%$ \\
\hline \multirow[t]{3}{*}{ Male } & & $0.3302 * * *$ & $0.2947 * * *$ & $0.3261 * * *$ & $0.3306^{* * *}$ & $0.3044 * * *$ & $0.2945 * * *$ \\
\hline & & $(115.42)$ & $(111.96)$ & $(114.97)$ & (116.24) & $(112.31)$ & $(112.16)$ \\
\hline & & $4.002 \%$ & $4.388 \%$ & $4.033 \%$ & $4.059 \%$ & $4.428 \%$ & $4.407 \%$ \\
\hline \multirow[t]{3}{*}{ Capacity } & & & $0.7241 * * *$ & & & & $0.6984 * * *$ \\
\hline & & & $(263.82)$ & & & & $(160.36)$ \\
\hline & & & $10.780 \%$ & & & $5.192 \%$ & $10.386 \%$ \\
\hline \multirow[t]{3}{*}{ Time } & & & & $0.2228 * * *$ & & & $0.1028 * * *$ \\
\hline & & & & $(88.69)$ & & & $(32.65)$ \\
\hline & & & & $2.756 \%$ & & $3.611 \%$ & $1.493 \%$ \\
\hline \multirow[t]{3}{*}{ Liquidity } & & & & & $0.1887 * * *$ & & $0.0532 * * *$ \\
\hline & & & & & $(74.36)$ & & $(19.41)$ \\
\hline & & & & & $2.317 \%$ & $2.655 \%$ & $0.763 \%$ \\
\hline \multirow[t]{3}{*}{ Capacity*Time*Liquidity } & & & & & & $0.1791 * * *$ & -0.0022 \\
\hline & & & & & & $(210.33)$ & $(-1.28)$ \\
\hline & & & & & & & - \\
\hline Observations & 480,949 & 480,949 & 480,949 & 480,949 & 480,949 & 480,949 & 480,949 \\
\hline Time FE (Year) & $\mathrm{Y}$ & Y & $\mathrm{Y}$ & $\mathrm{Y}$ & $\mathrm{Y}$ & $\mathrm{Y}$ & $\mathrm{Y}$ \\
\hline$\Delta$ Predicted ATR / Age $[30 ; 80]$ & 1.2479 & 1.1956 & 1.0691 & 0.9212 & 1.1935 & 0.8012 & 0.9512 \\
\hline Pseudo $\mathrm{R}^{2}$ & 0.0146 & 0.0259 & 0.0741 & 0.0309 & 0.0294 & 0.0565 & 0.0756 \\
\hline
\end{tabular}


Table 4: Attitude to risk, age and capacity, time and liquidity combinations - Ordered Probit regressions results

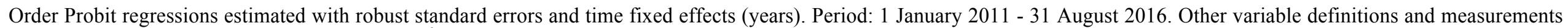

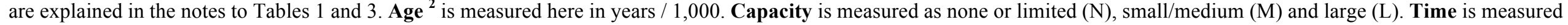

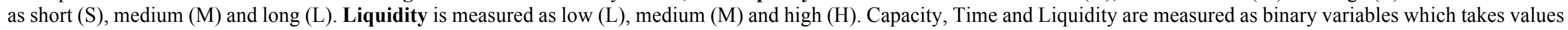

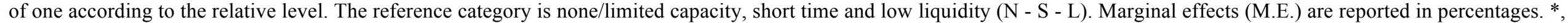

** and $* * *$ indicate significance at the $10 \%, 5 \%$ and $1 \%$ levels respectively.

\begin{tabular}{|c|c|c|c|c|c|c|c|c|c|c|c|c|}
\hline \multirow{2}{*}{$\begin{array}{c}\text { Dep. Var. } \\
\text { Calculated ATR }\end{array}$} & \multicolumn{3}{|c|}{ (1) } & \multicolumn{3}{|c|}{ (2) } & \multicolumn{3}{|c|}{ (3) } & \multicolumn{3}{|c|}{ (4) } \\
\hline & Coeff. & $\mathrm{z}$ & M.E. (\%) & Coeff. & $\mathrm{z}$ & M.E. (\%) & Coeff. & $\mathrm{z}$ & M.E. (\%) & Coeff. & $\mathrm{z}$ & M.E. $(\%)$ \\
\hline \multicolumn{13}{|l|}{ Ind. Variables: } \\
\hline Age & $-0.0120 * * *$ & -16.91 & $-0.201 \%$ & $-0.0156 * * *$ & -22.22 & $-0.201 \%$ & $-0.0136 * * *$ & -121.84 & $-0.213 \%$ & -0.0008 & -1.23 & $-0.211 \%$ \\
\hline $\mathrm{Age}^{2}$ & $-0.0501 * * *$ & -8.21 & - & $-0.0113 *$ & -1.88 & - & & & - & $-0.1129 * * *$ & -20.72 & - \\
\hline 10 Question version & & & & $-0.2352 * * *$ & -82.12 & $-2.851 \%$ & $-0.1928 * * *$ & -73.82 & $-3.021 \%$ & $-0.1921 * * *$ & -73.56 & $-2.924 \%$ \\
\hline Male & & & & $0.3302^{* * *}$ & 115.42 & $4.002 \%$ & $0.2954 * * *$ & 112.86 & $4.627 \%$ & $0.2924 * * *$ & 111.66 & $4.452 \%$ \\
\hline \multicolumn{13}{|l|}{ Capacity $*$ Time $*$ Liquidity: } \\
\hline $\mathrm{N}-\mathrm{S}-\mathrm{M}$ & & & & & & & $0.2716 * * *$ & 15.34 & $4.443 \%$ & $0.2728 * * *$ & 15.39 & $4.531 \%$ \\
\hline $\mathrm{N}-\mathrm{S}-\mathrm{H}$ & & & & & & & $0.3118^{* * *}$ & 18.46 & $5.192 \%$ & $0.3123 * * *$ & 18.47 & $5.276 \%$ \\
\hline$N-M-L$ & & & & & & & $0.2455^{* * *}$ & 12.74 & $3.968 \%$ & $0.2455^{* * *}$ & 12.73 & $4.029 \%$ \\
\hline$N-M-M$ & & & & & & & $0.3826 * * *$ & 23.94 & $6.560 \%$ & $0.3831 * * *$ & 23.96 & $6.655 \%$ \\
\hline $\mathrm{N}-\mathrm{M}-\mathrm{H}$ & & & & & & & $0.3725 * * *$ & 24.10 & $6.361 \%$ & $0.3735^{* * *}$ & 24.15 & $6.466 \%$ \\
\hline $\mathrm{N}-\mathrm{L}-\mathrm{L}$ & & & & & & & $0.2536^{* * *}$ & 9.98 & $4.114 \%$ & $0.2535^{* * *}$ & 9.97 & $4.175 \%$ \\
\hline$N-L-M$ & & & & & & & $0.3794 * * *$ & 21.18 & $6.496 \%$ & $0.3802 * * *$ & 21.23 & $6.599 \%$ \\
\hline $\mathrm{N}-\mathrm{L}-\mathrm{H}$ & & & & & & & $0.4056 * * *$ & 24.66 & $7.013 \%$ & $0.4091^{* * *}$ & 24.86 & $7.174 \%$ \\
\hline$M-S-L$ & & & & & & & $1.0104 * * *$ & 39.83 & $18.822 \%$ & $1.0115^{* * *}$ & 39.87 & $18.875 \%$ \\
\hline$M-S-M$ & & & & & & & $1.0816^{* * *}$ & 60.22 & $19.881 \%$ & $1.0851^{* * *}$ & 60.39 & $19.938 \%$ \\
\hline$M-S-H$ & & & & & & & $1.0884^{* * *}$ & 65.85 & $19.975 \%$ & $1.0915^{* * *}$ & 66.00 & $20.023 \%$ \\
\hline$M-M-L$ & & & & & & & $1.0629^{* * *}$ & 56.04 & $19.617 \%$ & $1.063 * * *$ & 56.03 & $19.635 \%$ \\
\hline$M-M-M$ & & & & & & & $1.1463^{* * *}$ & 74.92 & $20.723 \%$ & $1.1493^{* * *}$ & 75.08 & $20.738 \%$ \\
\hline$M-M-H$ & & & & & & & $1.1467 * * *$ & 76.45 & $20.728 \%$ & $1.1498^{* * *}$ & 76.62 & $20.744 \%$ \\
\hline$M-L-L$ & & & & & & & $1.1109 * * *$ & 50.55 & $20.278 \%$ & $1.1135^{* * *}$ & 50.71 & $20.307 \%$ \\
\hline$M-L-M$ & & & & & & & $1.2046^{* * *}$ & 75.69 & $21.370 \%$ & $1.2065^{* * *}$ & 75.79 & $21.342 \%$ \\
\hline$M-L-H$ & & & & & & & $1.2668^{* * *}$ & 83.36 & $21.937 \%$ & $1.2716^{* * *}$ & 83.63 & $21.894 \%$ \\
\hline$L-S-L$ & & & & & & & $1.2126^{* * *}$ & 12.01 & $21.451 \%$ & $1.2147 * * *$ & 12.04 & $21.420 \%$ \\
\hline L - S - M & & & & & & & $1.2372^{* * *}$ & 19.99 & $21.684 \%$ & $1.2461^{* * *}$ & 20.15 & $21.696 \%$ \\
\hline $\mathrm{L}-\mathrm{S}-\mathrm{H}$ & & & & & & & $1.4483^{* * *}$ & 40.90 & $22.792 \%$ & $1.4559 * * *$ & 41.13 & $22.614 \%$ \\
\hline$L-M-L$ & & & & & & & $1.3335 * * *$ & 24.05 & $22.394 \%$ & $1.3409^{* * *}$ & 24.19 & $22.315 \%$ \\
\hline$L-M-M$ & & & & & & & $1.5207 * * *$ & 61.39 & $22.784 \%$ & $1.5297 * * *$ & 61.76 & $22.539 \%$ \\
\hline $\mathrm{L}-\mathrm{M}-\mathrm{H}$ & & & & & & & $1.553 * * *$ & 92.75 & $22.715 \%$ & $1.5611^{* * *}$ & 93.17 & $22.443 \%$ \\
\hline$L-L-L$ & & & & & & & $1.6454 * * *$ & 21.05 & $22.299 \%$ & $1.6581^{* * *}$ & 21.22 & $21.913 \%$ \\
\hline$L-L-M$ & & & & & & & $1.8050^{* * *}$ & 58.36 & $20.861 \%$ & $1.8124 * * *$ & 58.63 & $20.388 \%$ \\
\hline$L-L-H$ & & & & & & & $1.8303 * * *$ & 105.56 & $20.555 \%$ & $1.8394 * * *$ & 106.02 & $20.042 \%$ \\
\hline Observations & 480,949 & & & 480,949 & & & 480,949 & & & 480,949 & & \\
\hline Time FE (Year) & $\mathrm{Y}$ & & & $\mathrm{Y}$ & & & Y & & & Y & & \\
\hline$\Delta$ Predicted ATR / Age $[30 ; 80]$ & 1.2479 & & & 1.1956 & & & 1.0093 & & & 0.9721 & & \\
\hline Pseudo $R^{2}$ & 0.0146 & & & 0.0259 & & & 0.0777 & & & 0.0780 & & \\
\hline
\end{tabular}




\section{Table 5: Attitude to risk, age and employment - Ordered Probit regressions results}

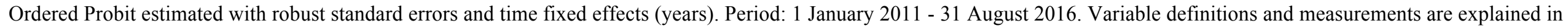

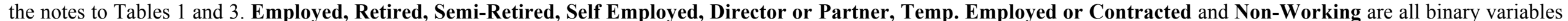

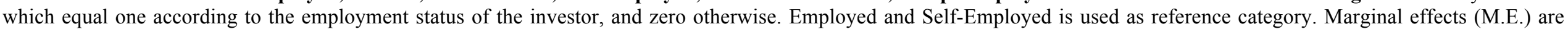
reported in percentagess. $* * *$ and $* * *$ indicate significance at the $10 \%, 5 \%$ and $1 \%$ levels respectively.

\begin{tabular}{|c|c|c|c|c|c|c|c|c|c|c|c|c|c|c|c|}
\hline \multirow{2}{*}{ Dep. Var. Calculated ATR } & \multicolumn{3}{|c|}{ (1) } & \multicolumn{3}{|c|}{ (2) } & \multicolumn{3}{|c|}{ (3) } & \multicolumn{3}{|c|}{ (4) } & \multicolumn{3}{|c|}{ (5) } \\
\hline & Coeff. & $\mathrm{z}$ & M.E. $(\%)$ & Coeff. & $\mathrm{z}$ & M.E. (\%) & Coeff. & $\mathrm{z}$ & M.E. $(\%)$ & Coeff. & $\mathrm{z}$ & M.E. (\%) & Coeff. & $\mathrm{z}$ & M.E. (\%) \\
\hline \multicolumn{16}{|l|}{ Ind. Variables: } \\
\hline Age & $-0.0156^{* * *}$ & -7.29 & $-0.190 \%$ & $-0.0198 * * *$ & -8.74 & $-0.200 \%$ & $-0.0051 * *$ & -2.39 & $-0.188 \%$ & $-0.0247 * * *$ & -10.85 & $-0.184 \%$ & $-0.0116^{* * *}$ & -5.41 & $-0.148 \%$ \\
\hline $\mathrm{Age}^{2}$ & $-0.0477 * *$ & -2.05 & - & -0.0040 & -0.20 & - & $-0.1050 * * *$ & -5.72 & - & $0.0591 * * *$ & 2.92 & - & -0.0105 & -0.55 & - \\
\hline 10 Question version & & & & $-0.2519 * * *$ & -23.92 & $-2.487 \%$ & $-0.1594 * * *$ & -16.21 & $-1.755 \%$ & $-0.2512 * * *$ & -23.94 & $-2.576 \%$ & $-0.1594 * * *$ & -16.27 & $-1.853 \%$ \\
\hline Male & & & & $0.3617 * * *$ & 40.00 & $3.570 \%$ & $0.3386^{* * *}$ & 39.52 & $3.728 \%$ & $0.3364 * * *$ & 36.80 & $3.449 \%$ & $0.3126^{* * *}$ & 36.16 & $3.635 \%$ \\
\hline Capacity & & & & & & & $0.5364 * * *$ & 38.00 & $5.612 \%$ & & & & $0.5420 * * *$ & 38.60 & $5.950 \%$ \\
\hline Time & & & & & & & $0.1386^{* * *}$ & 12.43 & $1.298 \%$ & & & & $0.1429 * * *$ & 12.86 & $1.388 \%$ \\
\hline Liquidity & & & & & & & $0.0499 * * *$ & 5.00 & $0.384 \%$ & & & & $0.0538 * * *$ & 5.40 & $0.427 \%$ \\
\hline Capacity*Time*Liquidity & & & & & & & $-0.0121 * *$ & -2.32 & - & & & & $-0.0138 * * *$ & -2.65 & - \\
\hline Employed & & & & & & & & & & $-0.1954 * * *$ & -4.79 & $-2.003 \%$ & $-0.1249 * * *$ & -3.16 & $-1.452 \%$ \\
\hline Retired & & & & & & & & & & $-0.2655^{* * *}$ & -6.33 & $-2.722 \%$ & $-0.2800^{* * *}$ & -6.90 & $-3.256 \%$ \\
\hline Semi-Retired & & & & & & & & & & $-0.1480 * * *$ & -2.86 & $-1.520 \%$ & $-0.1355^{* * *}$ & -2.72 & $-1.576 \%$ \\
\hline Self Employed & & & & & & & & & & $-0.0739 *$ & -1.75 & $-0.758 \%$ & -0.0293 & -0.72 & $-0.341 \%$ \\
\hline Director or Partner & & & & & & & & & & $0.0997 * *$ & 2.18 & $1.023 \%$ & $0.1175^{* * *}$ & 2.67 & $1.367 \%$ \\
\hline Temp. Employed or Contracted & & & & & & & & & & -0.0913 & -1.21 & $-0.936 \%$ & -0.0387 & -0.54 & $-0.450 \%$ \\
\hline Non-Working & & & & & & & & & & $-0.3043 * * *$ & -6.47 & $-3.120 \%$ & $-0.2009 * * *$ & -4.45 & $-2.336 \%$ \\
\hline Observations & 46,637 & & & 46,637 & & & 46,637 & & & 46,637 & & & 46,637 & & \\
\hline Time FE (Year) & $\mathrm{Y}$ & & & $\mathrm{Y}$ & & & $\mathrm{Y}$ & & & $\mathrm{Y}$ & & & $\mathrm{Y}$ & & \\
\hline$\Delta$ Predicted ATR / Age $[30 ; 80]$ & 1.5150 & & & 1.4350 & & & 1.1772 & & & 1.2882 & & & 0.8994 & & \\
\hline Pseudo $\mathrm{R}^{2}$ & 0.0217 & & & 0.0344 & & & 0.0662 & & & 0.0364 & & & 0.0687 & & \\
\hline
\end{tabular}




\section{Table 6: Attitude to risk, age and marital status - Ordered Probit regressions results}

Ordered Probit estimated with robust standard errors and time fixed effects (years). Period: 1 January 2011 - 31 August 2016. Additional variable definitions and measurements are explained in the notes to Tables 1 and 3. Civil Partnership, Married, Divorced and Widowed are all binary variables which equal one according to the marital status of the investor, and zero otherwise. Single is used as reference category. Z-tests are reported in brackets. Marginal effects are reported in percentages. $* * *$ and $* * *$ indicate significance at the $10 \%, 5 \%$ and $1 \%$ levels respectively.

\begin{tabular}{|c|c|c|c|c|c|}
\hline Dep. Var. Calculated ATR & (1) & $(2)$ & (3) & (4) & $(5)$ \\
\hline \multicolumn{6}{|l|}{ Ind. Variables: } \\
\hline \multirow[t]{3}{*}{ Age } & $-0.0170 * * *$ & $-0.0203 * * *$ & $-0.0032 * * *$ & $-0.0213 * * *$ & $-0.0044 * * *$ \\
\hline & $(-19.39)$ & $(-23.56)$ & $(-4.08)$ & $(-23.78)$ & $(-5.37)$ \\
\hline & $-0.222 \%$ & $-0.226 \%$ & $-0.230 \%$ & $-0.229 \%$ & $-0.231 \%$ \\
\hline \multirow[t]{3}{*}{ Age $^{2}$} & $-0.0138^{*}$ & $0.0223 * * *$ & $-0.0992 * * *$ & $0.0291 * * *$ & $-0.0893 * * *$ \\
\hline & $(-1.85)$ & $(3.03)$ & $(-14.81)$ & $(3.81)$ & $(-12.80)$ \\
\hline & - & - & - & - & - \\
\hline \multirow[t]{3}{*}{10 Question version } & & $-0.2279 * * *$ & $-0.1825^{* * *}$ & $-0.2276^{* * *}$ & $-0.1822 * * *$ \\
\hline & & $(-66.75)$ & $(-58.32)$ & $(-66.66)$ & $(-58.25)$ \\
\hline & & $-2.908 \%$ & $-2.841 \%$ & $-2.909 \%$ & $-2.845 \%$ \\
\hline \multirow[t]{3}{*}{ Male } & & $0.3240 * * *$ & $0.2940 * * *$ & $0.3242 * * *$ & $0.2942 * * *$ \\
\hline & & $(95.86)$ & $(94.52)$ & $(94.49)$ & $(93.20)$ \\
\hline & & $4.134 \%$ & $4.577 \%$ & $4.144 \%$ & $4.592 \%$ \\
\hline \multirow[t]{3}{*}{ Capacity } & & & $0.6887 * * *$ & & $0.6892 * * *$ \\
\hline & & & $(131.10)$ & & $(131.19)$ \\
\hline & & & $10.649 \%$ & & $10.682 \%$ \\
\hline \multirow[t]{3}{*}{ Time } & & & $0.1109 * * *$ & & $0.1109 * * *$ \\
\hline & & & $(28.89)$ & & $(28.88)$ \\
\hline & & & $1.675 \%$ & & $1.677 \%$ \\
\hline \multirow[t]{3}{*}{ Liquidity } & & & $0.0394 * * *$ & & $0.0398 * * *$ \\
\hline & & & $(11.84)$ & & (11.97) \\
\hline & & & $0.576 \%$ & & $0.582 \%$ \\
\hline \multirow[t]{3}{*}{ Capacity*Time*Liquidity } & & & -0.0023 & & -0.0025 \\
\hline & & & $(-1.14)$ & & $(-1.20)$ \\
\hline & & & - & & - \\
\hline \multirow[t]{3}{*}{ Civil Partnership } & & & & -0.0121 & -0.0205 \\
\hline & & & & $(-0.50)$ & $(-0.93)$ \\
\hline & & & & $-0.155 \%$ & $-0.319 \%$ \\
\hline \multirow[t]{3}{*}{ Married } & & & & $0.0253 * * *$ & $0.0166^{* * *}$ \\
\hline & & & & $(5.29)$ & $(3.80)$ \\
\hline & & & & $0.324 \%$ & $0.259 \%$ \\
\hline \multirow[t]{3}{*}{ Divorced } & & & & $0.0232 * * *$ & $0.0523 * * *$ \\
\hline & & & & $(2.66)$ & $(6.60)$ \\
\hline & & & & $0.296 \%$ & $0.816 \%$ \\
\hline \multirow[t]{3}{*}{ Widowed } & & & & $0.0255^{* * *}$ & 0.0019 \\
\hline & & & & $(3.14)$ & $(0.25)$ \\
\hline & & & & $0.326 \%$ & $0.030 \%$ \\
\hline Observations & 341,073 & 341,073 & 341,073 & 341,073 & 341,073 \\
\hline Time FE (Year) & $\mathrm{Y}$ & $\mathrm{Y}$ & $\mathrm{Y}$ & $\mathrm{Y}$ & $\mathrm{Y}$ \\
\hline$\Delta$ Predicted ATR / Age $[30 ; 80]$ & 1.3061 & 1.2614 & 0.9942 & 1.2757 & 0.9999 \\
\hline Pseudo $\mathrm{R}^{2}$ & 0.0156 & 0.0266 & 0.0750 & 0.0267 & 0.0750 \\
\hline
\end{tabular}




\section{Table 7: Attitude to risk, age and investment wealth - Ordered Probit regressions results}

Ordered Probit estimated with robust standard errors and time fixed effects (years). Period: 1 January 2011 - 31 August 2016. Other variable definitions and measurements are explained in the notes to Tables 1 and 3 . Investment Wealth is the investable wealth of clients (measured in thousands of pounds), and is winsorised at the $1 \%$ and $99 \%$ percentiles. Ztests are reported in brackets. Marginal effects are reported in percentages. $*, * *$ and $* * *$ indicate significance at the $10 \%$, $5 \%$ and $1 \%$ levels respectively.

\begin{tabular}{|c|c|c|c|c|c|}
\hline Dep. Var. Calculated ATR & $(1)$ & $(2)$ & (3) & (4) & (5) \\
\hline \multicolumn{6}{|l|}{ Ind. Variables: } \\
\hline \multirow[t]{3}{*}{ Age } & $-0.0167 * * *$ & $-0.0177 * * *$ & $-0.0085^{* * *}$ & $-0.0185 * * *$ & $-0.0091 * * *$ \\
\hline & $(-11.03)$ & $(-11.83)$ & $(-6.13)$ & $(-12.36)$ & $(-6.58)$ \\
\hline & $-0.279 \%$ & $-0.284 \%$ & $-0.287 \%$ & $-0.298 \%$ & $-0.296 \%$ \\
\hline \multirow[t]{3}{*}{ Age $^{2}$} & $-0.0412 * * *$ & $-0.0250 * *$ & $-0.0813 * * *$ & $-0.0244 * *$ & $-0.0802 * * *$ \\
\hline & $(-3.27)$ & $(-2.01)$ & $(-7.08)$ & $(-1.97)$ & $(-6.98)$ \\
\hline & - & - & - & - & - \\
\hline \multirow[t]{3}{*}{10 Question version } & & $-0.2434 * * *$ & $-0.1878 * * *$ & $-0.2294 * * *$ & $-0.1801 * * *$ \\
\hline & & $(-42.66)$ & $(-34.79)$ & $(-40.26)$ & $(-33.33)$ \\
\hline & & $-3.336 \%$ & $-2.935 \%$ & $-3.182 \%$ & $-2.829 \%$ \\
\hline \multirow[t]{3}{*}{ Male } & & $0.335 * * *$ & $0.3073^{* * *}$ & $0.3356^{* * *}$ & $0.3082 * * *$ \\
\hline & & $(60.70)$ & $(58.82)$ & $(61.03)$ & $(59.08)$ \\
\hline & & $4.592 \%$ & $4.802 \%$ & $4.654 \%$ & $4.843 \%$ \\
\hline \multirow[t]{3}{*}{ Capacity } & & & $0.5691 * * *$ & & $0.5609 * * *$ \\
\hline & & & $(62.80)$ & & $(61.92)$ \\
\hline & & & $8.763 \%$ & & $8.670 \%$ \\
\hline \multirow[t]{3}{*}{ Time } & & & $0.1256^{* * *}$ & & $0.1249 * * *$ \\
\hline & & & $(16.84)$ & & $(16.75)$ \\
\hline & & & $1.859 \%$ & & $1.848 \%$ \\
\hline \multirow[t]{3}{*}{ Liquidity } & & & $0.0147 * *$ & & 0.0099 \\
\hline & & & $(2.44)$ & & $(1.64)$ \\
\hline & & & $0.159 \%$ & & $0.077 \%$ \\
\hline \multirow[t]{3}{*}{ Capacity*Time*Liquidity } & & & -0.0043 & & -0.0047 \\
\hline & & & $(-1.13)$ & & $(-1.23)$ \\
\hline & & & - & & - \\
\hline \multirow[t]{3}{*}{ Investment Wealth } & & & & $0.0003 * * *$ & $0.0002 * * *$ \\
\hline & & & & $(30.35)$ & $(20.50)$ \\
\hline & & & & $0.004 \%$ & $0.003 \%$ \\
\hline Observations & 124,533 & 124,533 & 124,533 & 124,533 & 124,533 \\
\hline Time FE (Year) & $\mathrm{Y}$ & $\mathrm{Y}$ & $\mathrm{Y}$ & $\mathrm{Y}$ & $\mathrm{Y}$ \\
\hline$\Delta$ Predicted ATR / Age $[30 ; 80]$ & 1.4372 & 1.3817 & 1.1754 & 1.4313 & 1.2097 \\
\hline Pseudo $\mathrm{R}^{2}$ & 0.0223 & 0.0347 & 0.0668 & 0.0370 & 0.0678 \\
\hline
\end{tabular}




\section{Table 8: Attitude to risk, age and investment experience - Ordered Probit regressions results}

Ordered Probit estimated with robust standard errors and time fixed effects (years). Period: 1 January 2011 - 31 August 2016. Other variable definitions and measurements are explained in the notes to Tables 1 and 3 . Investment Experience is the investor's level of experience in investing and is measured as a score variable (0-2) according to whether the investor is not experienced and has no financial knowledge, whether he/she has medium level of experience and financial literacy, or whether the she is comfortable in investing and understand potential financial risks and rewards. Z-tests are reported in brackets. Marginal effects are reported in percentages. $* * *$ and $* * *$ indicate significance at the $10 \%, 5 \%$ and $1 \%$ levels respectively.

\begin{tabular}{|c|c|c|c|c|c|}
\hline Dep. Var. Calculated ATR & (1) & (2) & (3) & (4) & (5) \\
\hline \multicolumn{6}{|l|}{ Ind. Variables: } \\
\hline \multirow[t]{3}{*}{ Age } & $-0.0235 * * *$ & $-0.0275 * * *$ & $-0.0097 * *$ & $-0.0301 * * *$ & $-0.0144 * * *$ \\
\hline & $(-4.96)$ & $(-5.88)$ & $(-2.28)$ & $(-6.73)$ & $(-3.50)$ \\
\hline & $-0.203 \%$ & $-0.201 \%$ & $-0.234 \%$ & $-0.293 \%$ & $-0.309 \%$ \\
\hline \multirow[t]{3}{*}{$\mathrm{Age}^{2}$} & 0.0601 & $0.1021 * * *$ & -0.0386 & $0.0977 * * *$ & -0.0187 \\
\hline & $(-1.51)$ & $(-2.59)$ & $(-1.07)$ & $(2.60)$ & $(-0.54)$ \\
\hline & - & - & - & - & - \\
\hline \multirow[t]{3}{*}{10 Question version } & & $-0.1913 * * *$ & $-0.1572 * * *$ & $-0.1765 * * *$ & $-0.1523 * * *$ \\
\hline & & $(-10.75)$ & $(-9.72)$ & $(-10.66)$ & $(-9.86)$ \\
\hline & & $-2.502 \%$ & $-2.567 \%$ & $-2.794 \%$ & $-2.826 \%$ \\
\hline \multirow[t]{3}{*}{ Male } & & $0.2775^{* * *}$ & $0.2626^{* * *}$ & $0.1952 * * *$ & $0.2013 * * *$ \\
\hline & & $(15.54)$ & $(16.11)$ & $(11.66)$ & $(12.85)$ \\
\hline & & $3.628 \%$ & $4.289 \%$ & $3.090 \%$ & $3.735 \%$ \\
\hline \multirow[t]{3}{*}{ Capacity } & & & $0.7354 * * *$ & & $0.6182 * * *$ \\
\hline & & & $(26.66)$ & & $(23.50)$ \\
\hline & & & $11.956 \%$ & & $11.451 \%$ \\
\hline \multirow[t]{3}{*}{ Time } & & & $0.1108^{* * *}$ & & $0.1031 * * *$ \\
\hline & & & $(5.62)$ & & $(5.47)$ \\
\hline & & & $1.771 \%$ & & $1.900 \%$ \\
\hline \multirow[t]{3}{*}{ Liquidity } & & & $0.0865^{* * *}$ & & $0.0354 * * *$ \\
\hline & & & $(5.02)$ & & $(2.15)$ \\
\hline & & & $1.385 \%$ & & $0.648 \%$ \\
\hline \multirow[t]{3}{*}{ Capacity*Time*Liquidity } & & & -0.0016 & & -0.0005 \\
\hline & & & $(-0.15)$ & & $(-0.05)$ \\
\hline & & & - & & - \\
\hline \multirow[t]{3}{*}{ Investment Experience } & & & & $0.6060 * * *$ & $0.4643 * * *$ \\
\hline & & & & $(40.55)$ & $(32.63)$ \\
\hline & & & & $9.595 \%$ & $8.614 \%$ \\
\hline Observations & 12,541 & 12,541 & 12,541 & 12,541 & 12,541 \\
\hline Time FE (Year) & $\mathrm{Y}$ & $\mathrm{Y}$ & $\mathrm{Y}$ & $\mathrm{Y}$ & Y \\
\hline$\Delta$ Predicted ATR / Age $[30 ; 80]$ & 1.6138 & 1.8893 & 0.6677 & 2.0656 & 0.9915 \\
\hline Pseudo $\mathrm{R}^{2}$ & 0.0117 & 0.0197 & 0.0738 & 0.0601 & 0.0999 \\
\hline
\end{tabular}




\section{Table 9: Attitude to risk, age, health and smoking - Ordered Probit regressions results}

Ordered Probit estimated with robust standard errors and time fixed effects (years). Period: 1 January 2011 - 31 August 2016. Other variable definitions and measurements are explained in the notes to Tables 1 and 3. Good Health is a binary variable which equals one if the investor's health is good, and zero otherwise. Smoker is a binary variable which equals zero is the investor regularly smokes, and zero otherwise. Z-tests are reported in parentheses. Marginal effects are reported in percentages. $*, * *$ and $* * *$ indicate significance at the $10 \%, 5 \%$ and $1 \%$ levels respectively.

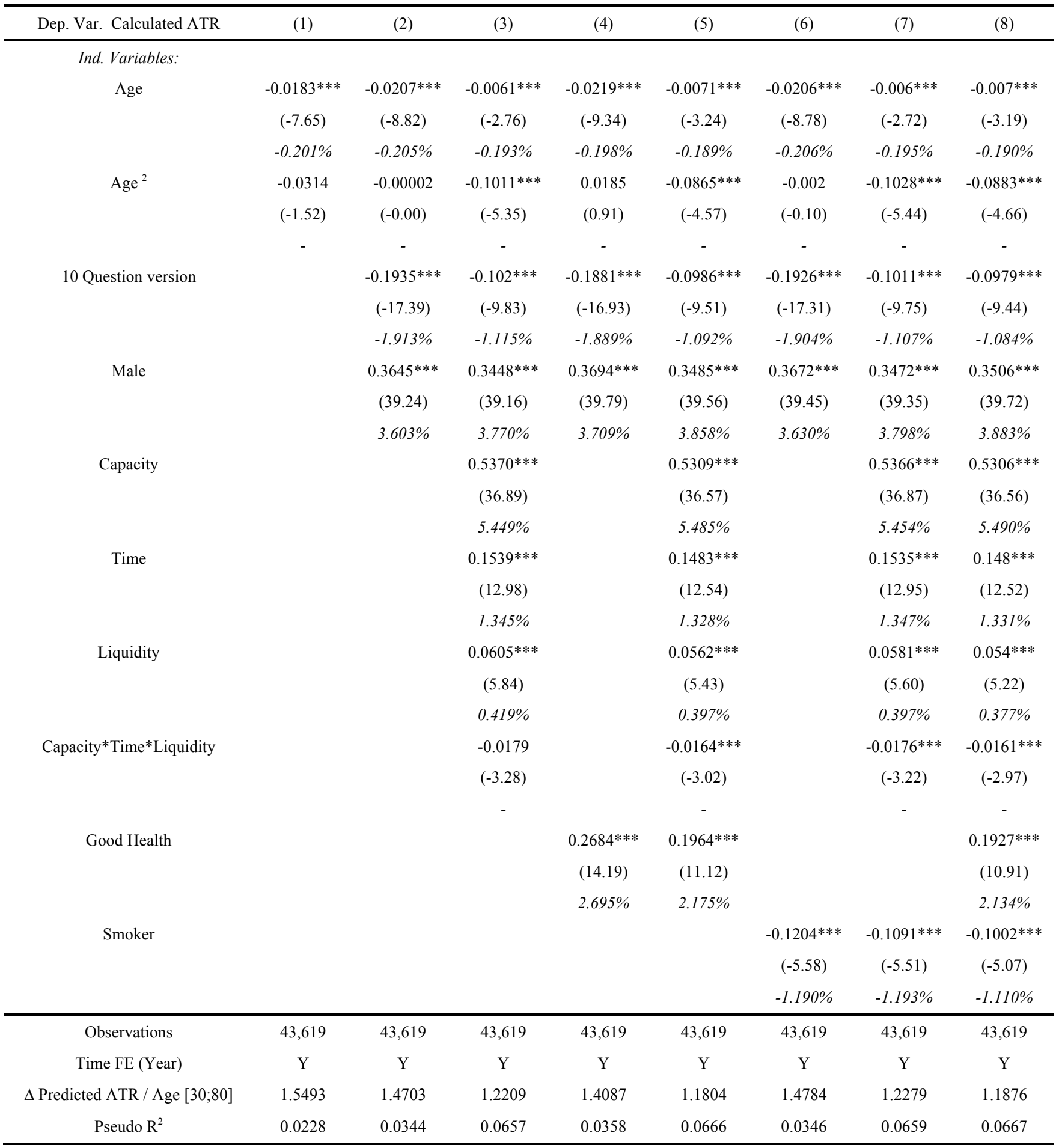


Table 10: Average percentage of middle answer by age

The Table reports the average percentage of middle answers by age bucket, gender and questionnaire version over the sample period 1 January 2011 to 31 August 2016.

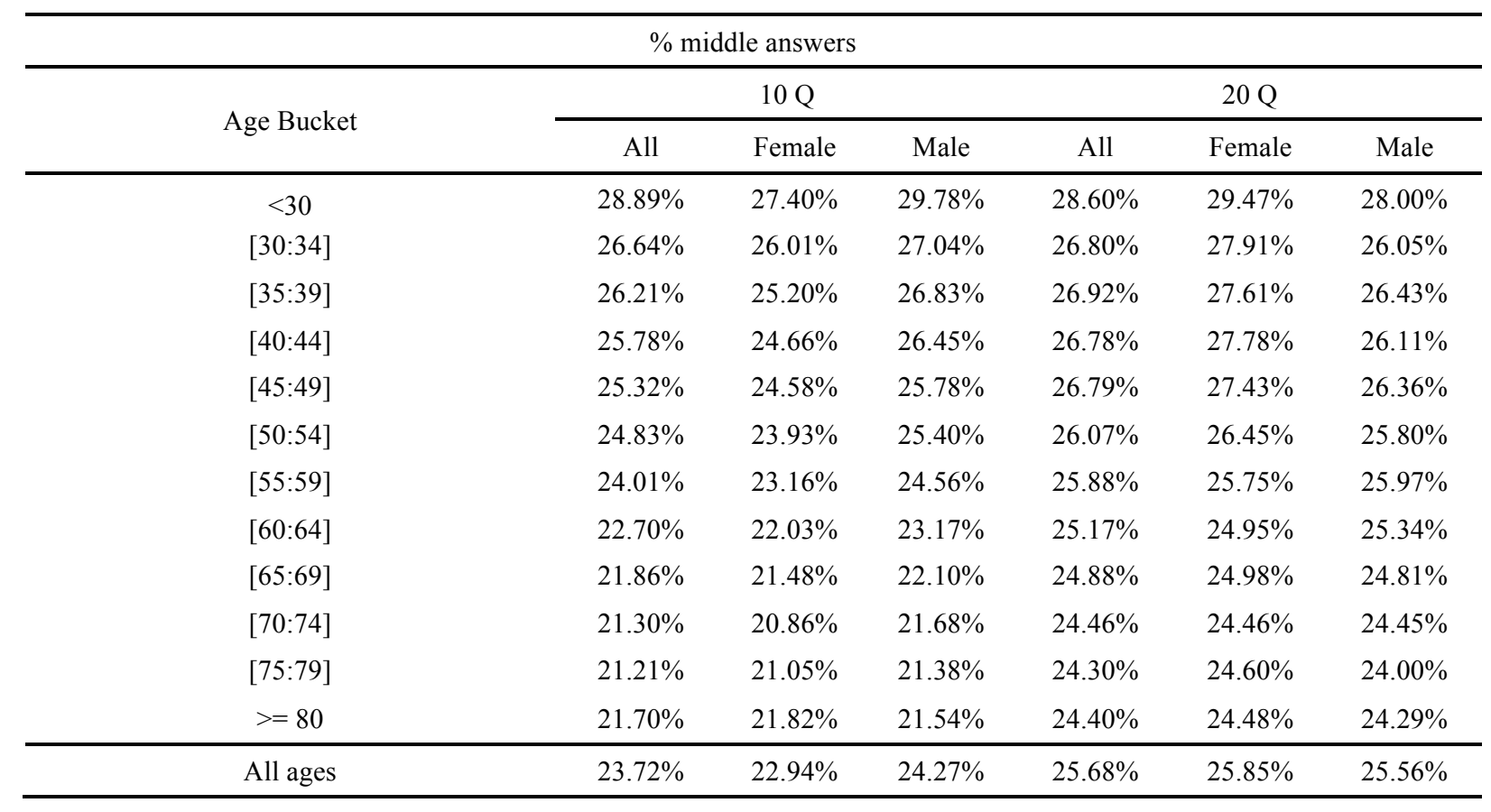

Table 11: Cronbach's Alpha by age

The Table reports summary statistics of the Cronbach's Alpha for each client by age bucket, gender and questionnaire version over the sample period 1 January 2011 to 31 August 2016.

\begin{tabular}{ccccccc}
\hline \multicolumn{7}{c}{ Cronbach's Alpha } \\
\hline \multirow{2}{*}{ Age Bucket } & \multicolumn{2}{c}{ Both Genders } & \multicolumn{2}{c}{$10 \mathrm{Q}$} & \multicolumn{2}{c}{$20 \mathrm{Q}$} \\
\cline { 2 - 7 } & $10 \mathrm{Q}$ & $20 \mathrm{Q}$ & Female & Male & Female & Male \\
\hline$<30$ & 0.8168 & 0.9159 & 0.8199 & 0.8081 & 0.9086 & 0.9138 \\
{$[30: 34]$} & 0.8242 & 0.9100 & 0.8153 & 0.8161 & 0.9116 & 0.8990 \\
{$[35: 39]$} & 0.8297 & 0.9105 & 0.8293 & 0.8167 & 0.9055 & 0.9052 \\
{$[40: 44]$} & 0.8353 & 0.9153 & 0.8290 & 0.8282 & 0.9110 & 0.9100 \\
{$[45: 49]$} & 0.8350 & 0.9138 & 0.8250 & 0.8308 & 0.9093 & 0.9092 \\
{$[50: 54]$} & 0.8319 & 0.9162 & 0.8152 & 0.8334 & 0.9111 & 0.9124 \\
{$[55: 59]$} & 0.8267 & 0.9129 & 0.8071 & 0.8306 & 0.9048 & 0.9127 \\
{$[60: 64]$} & 0.8129 & 0.9096 & 0.7925 & 0.8197 & 0.9008 & 0.9113 \\
{$[65: 69]$} & 0.7932 & 0.9056 & 0.7616 & 0.8071 & 0.8934 & 0.9098 \\
{$[70: 74]$} & 0.7638 & 0.8943 & 0.7491 & 0.7675 & 0.8843 & 0.8960 \\
{$[75: 79]$} & 0.7484 & 0.8938 & 0.7315 & 0.7546 & 0.8873 & 0.8948 \\
$>=80$ & 0.7425 & 0.8922 & 0.7345 & 0.7473 & 0.8893 & 0.8911 \\
\hline Total & 0.8230 & 0.9143 & 0.8019 & 0.8278 & 0.9053 & 0.9148 \\
\hline
\end{tabular}




\section{Figure 3: Middle answer bias, cognitive decline and age}

This figure shows the percentage of clients with at least $60 \%$ of middle answers for the 10 -question version of the questionnaire by gender in Panel A, the average standard deviation of responses with at least $60 \%$ of middle answers for the 10-question version of the by gender in Panel B, and the average absolute deviation of similar questions which measure same dimension of attitude to risk in the 20 -question version of the questionnaire in Panel C. Period from 1 January 2011 to 31 August 2016.

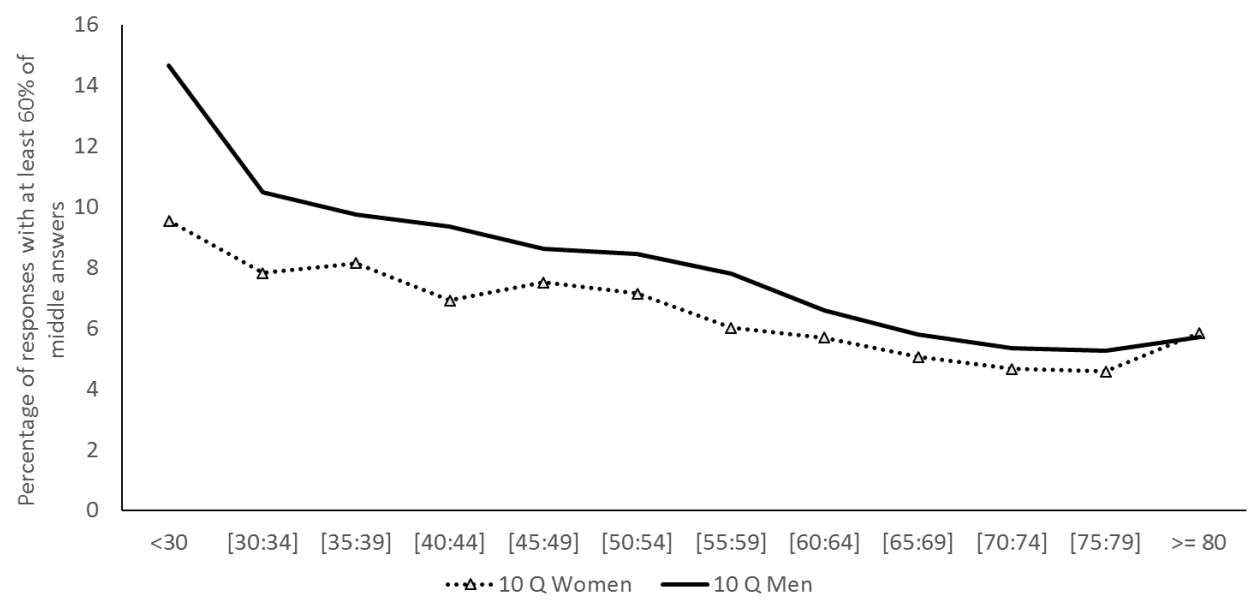

(a)

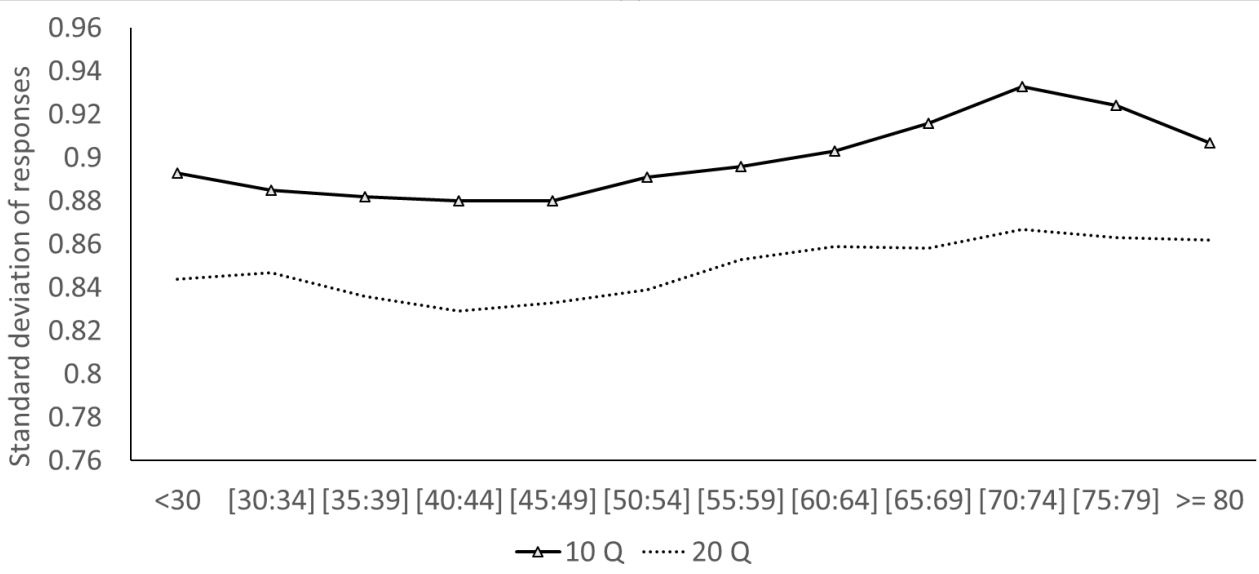

(b)

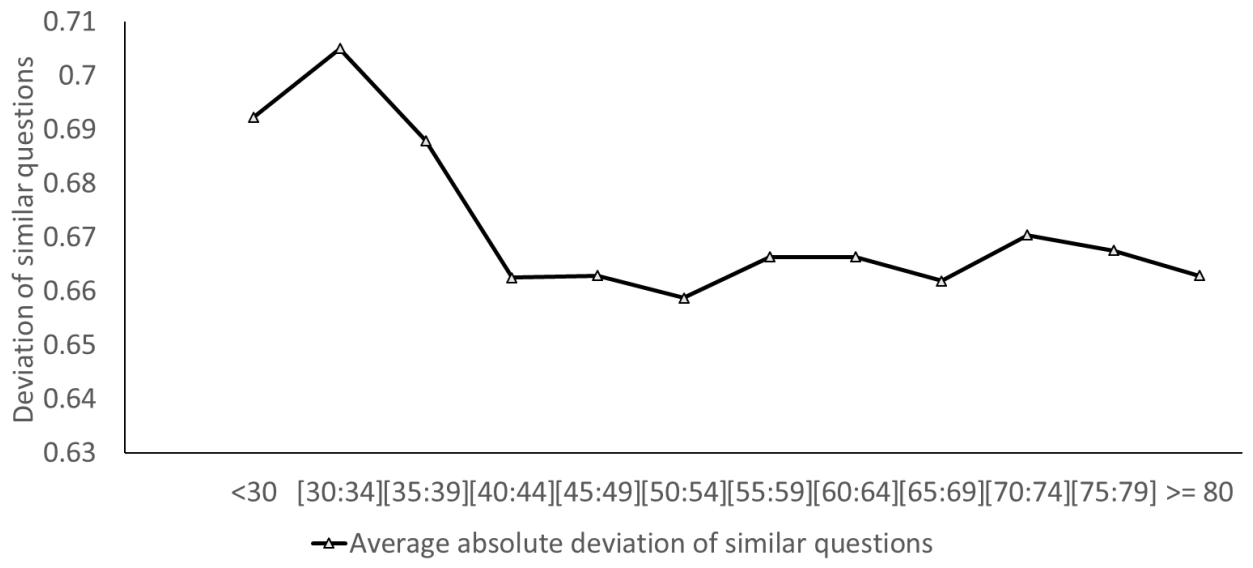

(c) 
Table 12: Attitude to risk, age cognitive decline and similar questions - Ordered Probit regressions

\section{results}

Ordered Probit estimated with robust standard errors and time fixed effects (years). Period: 1 January 2011 - 31 August 2016. Other variable definitions and measurements are explained in the notes to Tables 1 and 3. Standard deviation of responses measures the degree of consistency in the responses of a given client (measured as the standard deviation of score units). Absolute deviation of similar questions is the average across five pairs of questions of the absolute deviation between each of the two similar questions (measured in score units). Z-tests are reported in brackets. Marginal effects are reported in percentages. $*, * *$ and $* * *$ indicate significance at the $10 \%, 5 \%$ and $1 \%$ levels respectively.

\begin{tabular}{|c|c|c|c|c|c|c|c|}
\hline Dep. Var. Calculated ATR & (1) & (2) & (3) & (4) & (5) & (6) & (7) \\
\hline \multicolumn{8}{|l|}{ Ind. Variables: } \\
\hline \multirow[t]{3}{*}{ Age } & $-0.0118 * * *$ & 0.0010 & $-0.0148 * * *$ & 0.0008 & $-0.0156 * * *$ & 0.0004 & 0.0006 \\
\hline & $(-11.58)$ & $(1.10)$ & $(-14.92)$ & $(0.91)$ & $(-15.57)$ & $(0.42)$ & $(0.69)$ \\
\hline & $-0.160 \%$ & $-0.163 \%$ & $-0.160 \%$ & $-0.160 \%$ & $-0.165 \%$ & $-0.165 \%$ & $-0.161 \%$ \\
\hline \multirow{2}{*}{$\operatorname{Age}^{2}$} & $(-6.60)$ & $(-17.12)$ & $(-2.21)$ & $(-16.61)$ & $(-2.04)$ & $(-16.57)$ & $(-16.47)$ \\
\hline & - & - & - & - & - & - & - \\
\hline \multirow[t]{3}{*}{ Male } & & $0.3377 * * *$ & $0.3649 * * *$ & $0.3311 * * *$ & $0.3708 * * *$ & $0.3356^{* * *}$ & $0.331 * * *$ \\
\hline & & $(90.74)$ & $(91.20)$ & $(89.56)$ & $(92.22)$ & $(90.41)$ & $(89.58)$ \\
\hline & & $3.753 \%$ & $3.426 \%$ & $3.709 \%$ & $3.457 \%$ & $3.751 \%$ & $3.713 \%$ \\
\hline \multirow{2}{*}{ Capacity } & & (111.18) & & (111.49) & & $(111.27)$ & (111.49) \\
\hline & & $7.392 \%$ & & $7.342 \%$ & & $7.389 \%$ & $7.346 \%$ \\
\hline \multirow[t]{3}{*}{ Time } & & $0.1297 * * *$ & & $0.1330 * * *$ & & $0.1305^{* * *}$ & $0.1329 * * *$ \\
\hline & & $(28.46)$ & & $(29.05)$ & & $(28.63)$ & (29.04) \\
\hline & & $1.269 \%$ & & $1.232 \%$ & & $1.259 \%$ & $1.233 \%$ \\
\hline \multirow[t]{3}{*}{ Liquidity } & & $0.0517 * * *$ & & $0.0531 * * *$ & & $0.0527 * * *$ & $0.0533^{* * *}$ \\
\hline & & $(13.10)$ & & $(13.37)$ & & $(13.35)$ & $(13.42)$ \\
\hline & & $0.448 \%$ & & $0.406 \%$ & & $0.443 \%$ & $0.409 \%$ \\
\hline \multirow[t]{2}{*}{ Capacity*Time*Liquidity } & & $-0.0107 * * *$ & & $-0.0159 * * *$ & & $-0.0124 * * *$ & $-0.0159 * * *$ \\
\hline & & $(-4.38)$ & & $(-6.56)$ & & $(-5.09)$ & $(-6.56)$ \\
\hline \multirow[t]{3}{*}{ Standard deviation of responses } & & & $-0.7103 * * *$ & $-0.6105^{* * *}$ & & & $-0.5414 * * *$ \\
\hline & & & $(-52.30)$ & $(-50.50)$ & & & $(-40.95)$ \\
\hline & & & $-6.668 \%$ & $-6.840 \%$ & & & $-6.073 \%$ \\
\hline \multirow[t]{3}{*}{ Absolute deviation of similar questions } & & & & & $-0.2448 * * *$ & $-0.2112 * * *$ & $-0.0754 * * *$ \\
\hline & & & & & $(-44.49)$ & $(-41.48)$ & $(-13.84)$ \\
\hline & & & & & $-2.283 \%$ & $-2.361 \%$ & $-0.845 \%$ \\
\hline Observations & 243,841 & 243,841 & 243,841 & 243,841 & 243,841 & 243,841 & 243,841 \\
\hline Time FE (Year) & $\mathrm{Y}$ & $\mathrm{Y}$ & $\mathrm{Y}$ & $\mathrm{Y}$ & $\mathrm{Y}$ & $\mathrm{Y}$ & $\mathrm{Y}$ \\
\hline$\Delta$ Predicted ATR / Age $[30 ; 80]$ & 1.2785 & 0.9773 & 1.1899 & 0.9534 & 1.2337 & 0.9856 & 0.9591 \\
\hline Pseudo $\mathrm{R}^{2}$ & 0.0151 & 0.0717 & 0.0303 & 0.0764 & 0.0272 & 0.0737 & 0.0766 \\
\hline
\end{tabular}


Table 13: Attitude to risk, age, demographics and cognitive decline (summary) - Ordered Probit regressions

Ordered Probit estimated with robust standard errors and time fixed effects (years). Period: 1 January 2011 - 31 August 2016. Other Variable definitions and measurements are explained in previous tables. ${ }^{*} * *$ and $* * *$ indicate significance at the $10 \%, 5 \%$ and $1 \%$ levels respectively.

\begin{tabular}{|c|c|c|c|c|c|c|c|c|c|c|c|c|c|c|}
\hline \multirow{2}{*}{ Dep. Var. Calculated ATR } & \multicolumn{2}{|l|}{ (1) } & \multicolumn{2}{|c|}{ (2) } & \multicolumn{2}{|c|}{ (3) } & \multicolumn{2}{|c|}{ (4) } & \multicolumn{2}{|l|}{ (5) } & \multicolumn{2}{|c|}{ (6) } & \multicolumn{2}{|c|}{ (7) } \\
\hline & Coeff. & $\mathrm{z}$ & Coeff. & $\mathrm{z}$ & Coeff. & $\mathrm{z}$ & Coeff. & $\mathrm{z}$ & Coeff. & $\mathrm{z}$ & Coeff. & $\mathrm{z}$ & Coeff. & $\mathrm{z}$ \\
\hline \multicolumn{15}{|l|}{ Ind. Variables: } \\
\hline Age & $-0.0222 * * *$ & -6.75 & $-0.0105^{* * *}$ & -3.45 & $-0.0155^{* * *}$ & -5.13 & $-0.0159 * * *$ & -5.04 & $-0.0172^{* * *}$ & -5.47 & $-0.0176^{* * *}$ & -5.62 & $-0.0159 * * *$ & -5.08 \\
\hline $\mathrm{Age}^{2}$ & -0.0173 & -0.62 & -0.0859 & -3.32 & 0.0015 & 0.06 & 0.0023 & 0.08 & 0.0095 & 0.35 & 0.0156 & 0.58 & 0.0015 & 0.05 \\
\hline 10 Question version & & & $-0.1178 * * *$ & -7.17 & $-0.1178^{* * *}$ & -7.21 & $-0.1178^{* * *}$ & -7.21 & $-0.117^{* * *}$ & -7.17 & $-0.1161 * * *$ & -7.12 & $-0.0868^{* * *}$ & -5.21 \\
\hline Male & & & $0.3798 * * *$ & 32.73 & $0.3496^{* * *}$ & 29.94 & $0.3504 * * *$ & 29.46 & $0.3496 * * *$ & 29.48 & $0.3568 * * *$ & 29.98 & $0.3529 * * *$ & 29.76 \\
\hline Capacity & & & $0.3982 * * *$ & 20.42 & $0.4050 * * *$ & 20.90 & $0.4053^{* * *}$ & 20.92 & $0.3926^{* * *}$ & 20.34 & $0.3907 * * *$ & 20.30 & $0.3915 * * *$ & 20.34 \\
\hline Time & & & $0.1649^{* * *}$ & 9.49 & $0.1655^{* * *}$ & 9.58 & $0.1653^{* * *}$ & 9.57 & $0.1588 * * *$ & 9.20 & $0.1550^{* * *}$ & 9.01 & $0.1607 * * *$ & 9.29 \\
\hline Liquidity & & & -0.0133 & -0.90 & -0.0092 & -0.62 & -0.009 & -0.61 & $-0.0273^{*}$ & -1.84 & $-0.0310^{* *}$ & -2.09 & $-0.0310^{* *}$ & -2.08 \\
\hline Capacity*Time*Liquidity & & & -0.0036 & -0.48 & -0.0042 & -0.56 & -0.0043 & -0.58 & -0.0019 & -0.25 & -0.0013 & -0.17 & -0.0048 & -0.65 \\
\hline Employed & & & & & $-0.1571 * * *$ & -2.89 & $-0.1556^{* * *}$ & -2.86 & $-0.1588 * * *$ & -2.92 & $-0.1551 * * *$ & -2.86 & $-0.1491 * * *$ & -2.81 \\
\hline Retired & & & & & $-0.3303 * * *$ & -5.96 & $-0.3288 * * *$ & -5.93 & $-0.3462 * * *$ & -6.24 & $-0.3387 * * *$ & -6.11 & $-0.3294 * * *$ & -6.07 \\
\hline Semi-Retired & & & & & $-0.1386^{* *}$ & -2.13 & $-0.1370^{* *}$ & -2.11 & $-0.1487 * *$ & -2.29 & $-0.1445^{* *}$ & -2.23 & $-0.1321^{* *}$ & -2.07 \\
\hline Self Employed & & & & & -0.0337 & -0.60 & -0.0318 & -0.56 & -0.04 & -0.71 & -0.0354 & -0.63 & -0.0352 & -0.64 \\
\hline Director or Partner & & & & & $0.1075^{*}$ & 1.77 & $0.1095^{*}$ & 1.81 & 0.0933 & 1.53 & 0.0986 & 1.62 & $0.0979 *$ & 1.65 \\
\hline Temp. Employed or Contracted & & & & & -0.0919 & -0.93 & -0.0887 & -0.90 & -0.0962 & -0.98 & -0.0931 & -0.95 & -0.0725 & -0.76 \\
\hline Non-Working & & & & & $-0.2411 * * *$ & -3.85 & $-0.2390 * * *$ & -3.82 & $-0.2763^{* * *}$ & -4.41 & $-0.2625 * * *$ & -4.20 & $-0.2584 * * *$ & -4.21 \\
\hline Civil Partnership & & & & & & & -0.0459 & -0.56 & -0.0254 & -0.31 & -0.033 & -0.40 & -0.0305 & -0.38 \\
\hline Married & & & & & & & 0.0241 & 1.39 & 0.0184 & 1.07 & 0.0123 & 0.71 & 0.0119 & 0.69 \\
\hline Divorced & & & & & & & -0.0048 & -0.17 & -0.0013 & -0.04 & -0.0009 & -0.03 & -0.0011 & -0.04 \\
\hline Widowed & & & & & & & 0.0367 & 1.36 & 0.0343 & 1.28 & 0.0348 & 1.30 & 0.0304 & 1.13 \\
\hline Investment Wealth & & & & & & & & & $0.0002 * * *$ & 13.35 & $0.0002 * * *$ & 13.13 & $0.0002 * * *$ & 13.25 \\
\hline Good Health & & & & & & & & & & & $0.1470 * * *$ & 6.42 & $0.1517 * * *$ & 6.54 \\
\hline Smoker & & & & & & & & & & & $-0.1293 * * *$ & -4.64 & $-0.1315^{* * *}$ & -4.72 \\
\hline Standard deviation of responses & & & & & & & & & & & & & $-0.4027 * * *$ & -11.66 \\
\hline Observations & 25,462 & & 25,462 & & 25,462 & & 25,462 & & 25,462 & & 25,462 & & 25,462 & \\
\hline Time FE (Year) & $\mathrm{Y}$ & & $\mathrm{Y}$ & & $\mathrm{Y}$ & & $\mathrm{Y}$ & & $\mathrm{Y}$ & & $\mathrm{Y}$ & & $\mathrm{Y}$ & \\
\hline$\Delta$ Predicted ATR / Age $[30 ; 80]$ & 1.6575 & & 1.3753 & & 1.0583 & & 1.0738 & & 1.1100 & & 1.0940 & & 1.0800 & \\
\hline Pseudo $\mathrm{R}^{2}$ & 0.0282 & & 0.0627 & & 0.0661 & & 0.0661 & & 0.0684 & & 0.0691 & & 0.0715 & \\
\hline
\end{tabular}

